\title{
Fauna de hidroides (Cnidaria, Hydrozoa) da região de Bombinhas, Santa Catarina, Brasil
}

\author{
Thaís Pires Miranda ${ }^{1,4}$, Maria Angélica Haddad ${ }^{2}$, Vanessa Shimabukuro ${ }^{1}$, \\ Janete Dubiaski-Silva ${ }^{3}$ \& Antonio Carlos Marques ${ }^{1}$ \\ ${ }^{1}$ Departamento de Zoologia, Instituto de Biociências, Universidade de São Paulo - USP, \\ Rua Matão, Trav. 14, 101, CEP 05508-090, São Paulo, SP, Brasil \\ ${ }^{2}$ Departamento de Zoologia, Setor de Ciências Biológicas, Universidade Federal do Paraná - UFPR, \\ CP 19020, CEP 81531-980, Curitiba, PR, Brasil \\ ${ }^{3}$ Pontifícia Universidade Católica do Paraná - PUCPR, Rua Imaculada Conceição, 1155, \\ CEP 80215-901, Curitiba, PR, Brasil \\ ${ }^{4}$ Autor para correspondência: Thaís Pires Miranda, e-mail: thaispmir@ib.usp.br
}

MIRANDA, T.P., HADDAD, M.A., SHIMABUKURO, V., DUBIASKI-SILVA, J. \& MARQUES, A.C. Hydroid fauna (Cnidaria, Hydrozoa) from the region of Bombinhas, Santa Catarina, Brazil. Biota Neotrop. 11(3): http://www.biotaneotropica.org.br/v11n3/en/abstract?inventory+bn03211032011

\begin{abstract}
The benthic hydroid fauna from shallow subtidal zone of six localities in the municipality of Bombinhas (state of Santa Catarina, Brazil) was surveyed and its morphology analysed. Cnidome was also examined when it was necessary for species identification. Twenty five morphospecies were found, from which five (20\%) were recorded for the first time in Santa Catarina State and three (12\%) were recorded for the first time in the south region of Brazil. There was a $12 \%$ and $5.5 \%$ increase in the records of benthic hydroid species for Santa Catarina and southern Brazilian coast, respectively.

Keywords: Anthoathecata, Leptothecata, biodiversity, faunistic, taxonomy, marine fauna, cnidarians.
\end{abstract}

MIRANDA, T.P., HADDAD, M.A., SHIMABUKURO, V., DUBIASKI-SILVA, J. \& MARQUES, A.C. Fauna de hidroides (Cnidaria, Hydrozoa) da região de Bombinhas, Santa Catarina, Brasil. Biota Neotrop. 11(3): http://www.biotaneotropica.org.br/v11n3/pt/abstract?inventory+bn03211032011

Resumo: A fauna de hidroides bentônicos do infralitoral raso, de seis locais do município de Bombinhas (Santa Catarina, Brasil), foi pesquisada e analisada com base na morfologia. O cnidoma foi examinado quando necessário para a identificação específica. Foram encontradas 25 espécies, das quais cinco (20\%) são registradas pela primeira vez para o estado de Santa Catarina e três (12\%) são registradas pela primeira vez para a região sul do Brasil. Houve um acréscimo de $12 \%$ e 5,5\% nos registros de espécies de hidroides para Santa Catarina e litoral sul brasileiro, respectivamente.

Palavras-chave: Anthoathecata, Leptothecata, biodiversidade, faunística, taxonomia, fauna marinha, cnidários. 


\section{Introdução}

A biodiversidade marinha brasileira é carente de estudos, fato agravado pela grande extensão territorial e ampla variedade de ecossistemas que caracterizam nossa costa e plataforma (Marques et al. 2003, Marques \& Lamas 2006, Migotto \& Marques 2006). Em uma avaliação do conhecimento sobre a biodiversidade marinha, Migotto \& Marques (2006:165) consideraram que a fauna brasileira "[...] está bastante aquém do conhecimento para o mundo." A região Sul do Brasil, incluindo o estado de Santa Catarina, não é exceção na escassez de conhecimento sobre a biodiversidade. Dentre os representantes desta fauna marinha, relativamente pouco conhecida, encontram-se os cnidários bentônicos (Migotto et al. 2002, Marques et al. 2003, Migotto \& Marques 2006).

Dentre o subfilo Medusozoa (filo Cnidaria), a classe Hydrozoa é a que apresenta a maior riqueza específica, com um total estimado de 3465 espécies descritas (Schuchert 2011). Por sua vez, dentre os hidrozoários, os grupos com mais espécies registradas são as subclasses Leptothecata e Anthoathecata, comumente tratados por "tecados" e "atecados", respectivamente. As espécies dessas subclasses são coloquialmente referidas como "hidroides".

Até o momento estão registradas 89 espécies de Hydrozoa para o estado de Santa Catarina, das quais nove são de Anthoathecata e seis de Leptothecata (a partir de Marques et al. (2003), dados atualizados). Para uma comparação, há 212 espécies de Hydrozoa registradas para o estado de São Paulo, sendo 52 de Anthoathecata e 79 de Leptothecata (Marques et al. 2003). Estes dados indicam que a biodiversidade de hidroides de Santa Catarina está subestimada devido à carência de estudos faunísticos específicos. Como dados faunísticos são a base para a compreensão da evolução e ecologia da biota, estudos faunísticos detalhados para a região são amplamente necessários. Estes dados podem influenciar desde o uso sustentado dos recursos da região até inferências mais amplas em diferentes áreas do conhecimento, como ecologia, biogeografia e taxonomia.

Com o objetivo de aumentar o conhecimento da fauna marinha, procedemos a um levantamento faunístico e taxonômico dos hidroides bentônicos da região de Bombinhas, estado de Santa Catarina.

\section{Material e Métodos}

As coletas foram qualitativas e feitas por mergulho, no infralitoral das praias de Bombas, Canto Grande, Quatro Ilhas, Sepultura e Tainha (Figura 1). O esforço amostral foi maior na Ponta das Garoupas, onde amostras de Sargassum cymosum C. Agardh foram coletadas sazonalmente durante outubro de 1993 e agosto de 1994, nos estratos superior (0 a 1,5 m), médio (1,5 a $3 \mathrm{~m}$ ) e inferior (4 m).

$\mathrm{O}$ material coletado foi anestesiado em solução marinha de $\mathrm{MgCl}_{2}$ a 7,5\% e fixado em solução de formalina a $10 \%$ ou etanol a $92,5 \%$.

As identificações foram feitas por comparação com descrições da literatura específica (Calder 1988, 1991, 1997, Migotto 1996) e com materiais de museus. Para a identificação das espécies de Eudendrium, fez-se análise de cnidoma, com medidas de cápsulas não explodidas dos nematocistos. A terminologia usada para o cnidoma foi a de Marques (2001).

Os materiais foram documentados fotograficamente, sendo que para algumas espécies menores, como Filellum sp. e Pycnotheca mirabilis, procedemos a estudos morfológicos por meio de microscopia eletrônica de varredura (MEV). A preparação para a MEV consistiu na desidratação do material em série de álcool, secagem até o ponto crítico, montagem e metalização com banho de ouro (ver procedimento geral em Shimabukuro \& Marques 2006).

Cada espécie é apresentada incluindo a sinonímia com todos os registros da mesma para o Brasil. Para a sinonímia mais completa

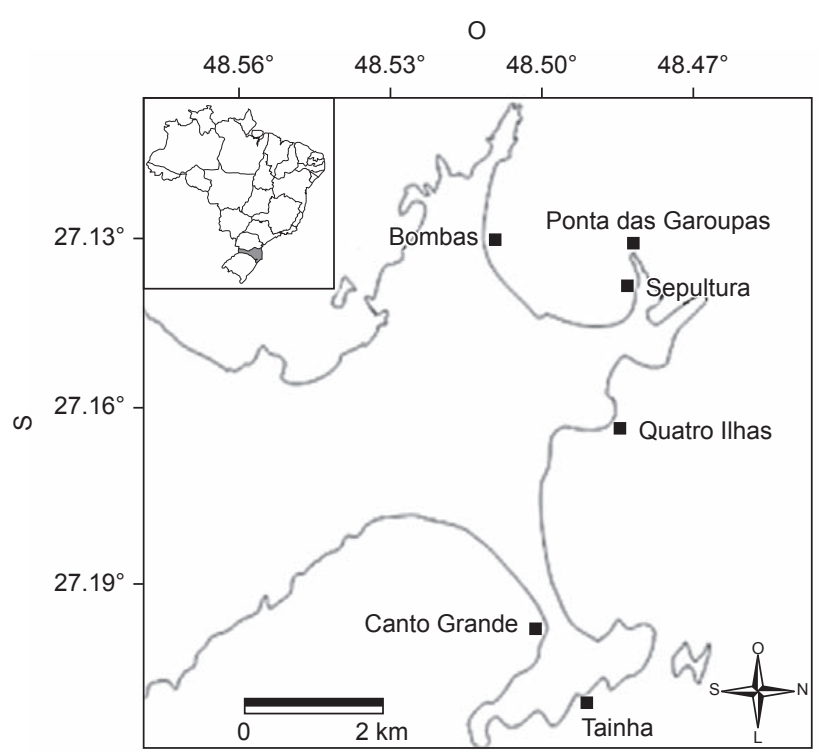

Figura 1. Mapa do município de Bombinhas com os pontos de coletas indicados.

Figure 1. Map of the district of Bombinhas with collection points indicated.

de algumas espécies são citados os trabalhos de Cornelius (1975), Calder (1988, 1991, 1997), Hirohito (1988), Marques et al. (2000), Marques (2001) e Campos et al. (2007), os quais incluem a maior parte dos registros das espécies para o mundo. Uma lista das espécies já registradas para Santa Catarina, juntamente com os registros mais austrais das mesmas, é apresentada com base em uma revisão dos dados da literatura até o ano de 2010 das espécies de Hydrozoa da América do Sul. Essas informações estão sendo aqui referidas como Oliveira et al. (dados não publicados) - os dados de Hydrozoa polipoides sul-americanos desse trabalho são de inteira responbilidade de T.P. Miranda e A.C. Marques.

Os materiais identificados foram incorporados à Coleção de Invertebrados Marinhos do Museu de Zoologia da Universidade de São Paulo (MZUSP) e à coleção do Departamento de Zoologia da Universidade Federal do Paraná (DZOO-UFPR).

\section{Resultados}

\section{Lista dos pontos, datas de coletas e espécies encontradas}

\section{Ponta das Garoupas ( $27^{\circ} 8{ }^{\prime} 3,27$ ' S e $48^{\circ} 28^{\prime} 42,72$ ' $\left.\mathrm{O}\right)$, 0-5 m.}

\section{X.1993, 11.I.1994, 28.V.1994, 13.VIII.1994.}

Aglaophenia latecarinata, Cladocoryne floccosa, Clytia gracilis, Dynamena disticha, Dynamena quadridentata, Filellum sp., Halecium dyssymetrum, Monotheca margaretta, Obelia dichotoma, Obelia geniculata, Orthopyxis integra, Orthopyxis sargassicola, Pycnotheca mirabilis, Sertularella conica, Sertularia distans, Sertularia turbinata.

Praia de Bombas $\left(27^{\circ} 7^{\prime}\right.$ 52,44' S e 48 30' 49,02' O $)$, 0-1 m.

\section{XI.2005, 14.XI.2005.}

A. latecarinata, D. disticha, Eudendrium carneum, Hebella scandens, O. dichotoma, O. geniculata, O. integra, O. sargassicola, Sertularia marginata, S. turbinata. 
Praia de Quatro Ilhas (27 ${ }^{\circ}{ }^{\prime} 11,40$ ' $\mathrm{S}$ e $48^{\circ} 28^{\prime}$ 50,08” O), 1-2 m.

\section{XII.2002}

A. latecarinata, Bougainvillia muscus, C. gracilis, E. carneum, Filellum sp., Halecium tenellum, M. margaretta, O. dichotoma, O. integra, S. marginata, S. turbinata.

Praia da Sepultura $\left(27^{\circ} 8\right.$ ' 29,14" S e $48^{\circ} 28{ }^{\prime} 41,39$ " O), 0-1 m.

\section{XII.2002}

A. latecarinata, C. gracilis, D. disticha, E. carneum, Macrorhynchia philippina, S. marginata, S. turbinata.

Praia do Canto Grande ( $27^{\circ} 12$ ' 3,73”' S e 48 ${ }^{\circ} 29^{\prime} 56.7^{\prime}$ ' O), 0-2 m.

\section{XII.2002}

S. turbinata.

Praia da Tainha $\left(27^{\circ} 12\right.$ ' 59,12"' S e 48 30 ' 34,42” O $)$, 0-2 m.

\section{XII.2002}

A. latecarinata, Bimeria vestita, C. gracilis, E. carneum, H. tenellum, M. philippina, M. margaretta, O. dichotoma, $P$. mirabilis, S.marginata, Sphaerocoryne sp., Zyzzyzus warreni.

\section{Parte taxonômica}

Subclasse Anthoathecata Cornelius 1992

Ordem Capitata Kühn 1913

\section{FAMÍLIA CLADOCORYNIDAE Allman 1872}

Cladocoryne floccosa Rotch 1871. (Figura 2a-b)

Cladocoryne floccosa Rotch 1871:228; Hirohito 1988:52-53, Figura 16b-f; Migotto 1996:17-18, Figura 4a-b.

[Sinonímia mais completa em Hirohito 1988:52]

Material: Ponta das Garoupas, gonóforos presentes, sobre Sargassum cymosum, 4 m, 16.X.1993, J. Dubiaski col. (MZUSP 4054).

Descrição: colônias eretas, altura $2-4 \mathrm{~mm}(\mathrm{n}=3)$, não ramificadas, surgindo diretamente da hidrorriza ramificada com rugosidades; diâmetro 111-191 $\mu \mathrm{m}(\mathrm{n}=10)$. Hidrocaule com perissarco rugoso e anelações na base; comprimento 2000-3670 $\mu \mathrm{m}(\mathrm{n}=3)$, diâmetro 133-167 $\mu \mathrm{m}(\mathrm{n}=3)$. Hidrante cilíndrico, comprimento 566-900 $\mu \mathrm{m}(\mathrm{n}=3)$, diâmetro 300-
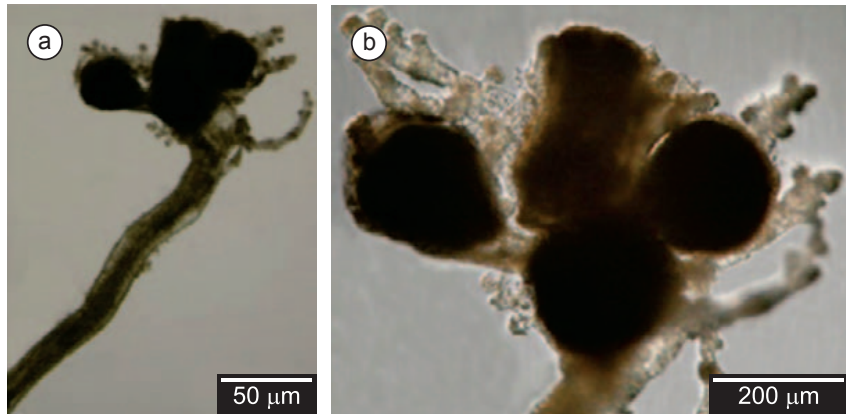

Figura 2. Cladocoryne floccosa Rotch 1871. a) Aspecto geral do pólipo e b) detalhe do hidrante com gonóforos.

Figure 2. Cladocoryne floccosa Rotch 1871. a) General aspect of the polyp and b) detail of hydranth with gonophores.
$366 \mu \mathrm{m}(\mathrm{n}=3)$. Um verticilo de tentáculos orais capitados, um ou dois verticilos de oito tentáculos aborais capitados e ramificados, dispostos irregularmente e com duas fileiras de capítulos pedicelados. Três gonóforos criptomedusoides, esféricos, com pedículos curtos surgindo do hidrante entre os tentáculos aborais; comprimento 317-444 $\mu \mathrm{m}(\mathrm{n}=3)$, diâmetro 317-333 $\mu \mathrm{m}(\mathrm{n}=3)$.

Comentários: encontramos três indivíduos epifíticos de Sargassum cymosum, sendo que dois estavam danificados e contraídos. O único indivíduo fértil tem o hipostômio pouco visível e apenas três gonóforos. Não há diferenças significativas em relação ao material descrito por Migotto (1996).

Distribuição: Cladocoryne floccosa foi registrada para o Brasil nas regiões Nordeste e Sudeste, para a área incluída entre os estados de Pernambuco e São Paulo (Migotto et al. 2002, Oliveira et al. 2006, Oliveira \& Marques 2007, Oliveira et al., no prelo). Este é o primeiro registro da espécie para a região Sul do Brasil e estado de Santa Catarina.

\section{FAMÍLIA SPHAEROCORYNIDAE Prévot 1959}

Sphaerocoryne sp. (Figura 3)

Material: Praia da Tainha, gonóforos ausentes, sobre porífero, 31.XII.2002, A.C. Marques col. (MZUSP 4044).

Descrição: indivíduo com altura $2,5 \mathrm{~mm}$, hidrocaule com perissarco fino e liso até base do hidrante; comprimento $1940 \mu \mathrm{m}$, diâmetro $120 \mu \mathrm{m}$. Hidrante na forma de cone invertido, comprimento $210 \mu \mathrm{m}$, diâmetro $200 \mu \mathrm{m}$. Dezessete tentáculos capitados dispostos irregularmente no terço aboral do hidrante. Gonóforos não observados.

Comentários: apenas um indivíduo foi coletado, epizoico em porífero não identificado. A identificação específica não é possível devido à falta de gonóforos, mas a morfologia do indivíduo é concordante com a descrição de Calder (1988) para esse gênero.

Distribuição: o gênero Sphaerocoryne foi registrado para o Brasil nas regiões Nordeste e Sudeste, para o estado do Ceará como ?Sphaerocoryne sp., e para os estados da Bahia e Espírito Santo como Sphaerocoryne sp. As únicas espécies desse gênero registradas para o Brasil são Sphaerocoryne arcuata (somente medusa, sem uma localidade específica), Sphaerocoryne bedoti e Sphaerocoryne ?bedoti, ambas somente no estágio de pólipo, para o estado do Espírito Santo (Migotto et al. 2002, Grohmann et al. 2003, Grohmann 2006, Marques et al. 2006, Oliveira et al., no prelo).

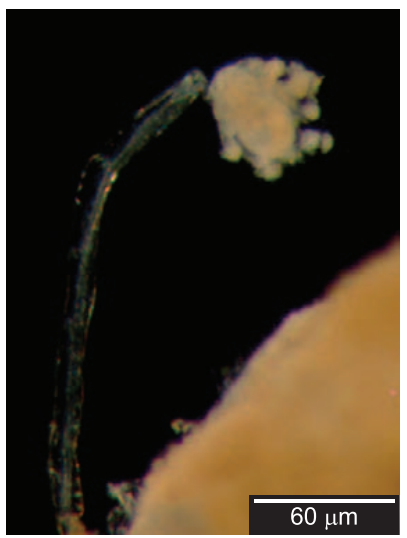

Figura 3. Aspecto geral de Sphaerocoryne sp.

Figure 3. General aspect of Sphaerocoryne sp. 
FAMÍLIA TUBULARIIDAE Fleming 1828

Zyzzyzus warreni Calder 1988. (Figura 4a-c)

Tubularia solitaria Warren 1908:83-93, pl. 10, Figuras 1-10, pl. 11, Figuras 11-26.

Zyzzyzus solitarius; Millard 1975:40, Figura 16a-b; Migotto \& da Silveira 1987:104-106, Figuras 4-5.

Zyzzyzus warreni Calder 1988:49-51, Figuras 38-40a-h; Migotto 1996:25; Campos et al. 2007:12-20, Figura 1a-h.

[Sinonímia mais completa em Campos et al. 2007:12]

Material: Praia da Tainha, gonóforos presentes, sobre porífero, 31.XII.2002, A.C. Marques col. (MZUSP 4045).

Descrição: pólipos com altura 4-9 mm $(\mathrm{n}=10)$, crescendo entre esponja. Processos de ancoragem digitiformes, alguns bulbosos, surgindo da região basal da hidrorriza ou da região mediana do hidrocaule; comprimento 397-2619 $\mu \mathrm{m}(\mathrm{n}=10)$, diâmetro 63-413 $\mu \mathrm{m}(\mathrm{n}=10)$. Hidrocaule alargado na região mediana, estreitando-se distalmente; comprimento 3100-8200 $\mu \mathrm{m}(\mathrm{n}=10)$, diâmetro proximal 500-980 $\mu \mathrm{m}(\mathrm{n}=10)$, diâmetro mediano 540-1000 $\mu \mathrm{m}(\mathrm{n}=10)$, diâmetro distal 460-800 $\mu \mathrm{m}(\mathrm{n}=10)$. Sulco anelar na porção distal do hidrocaule demarcando região de secreção do perissarco; perissarco fino e flexível. Cenossarco do hidrocaule com canais endodérmicos longitudinais alinhados paralelamente na região distal do hidrocaule. Hidrante vasiforme,
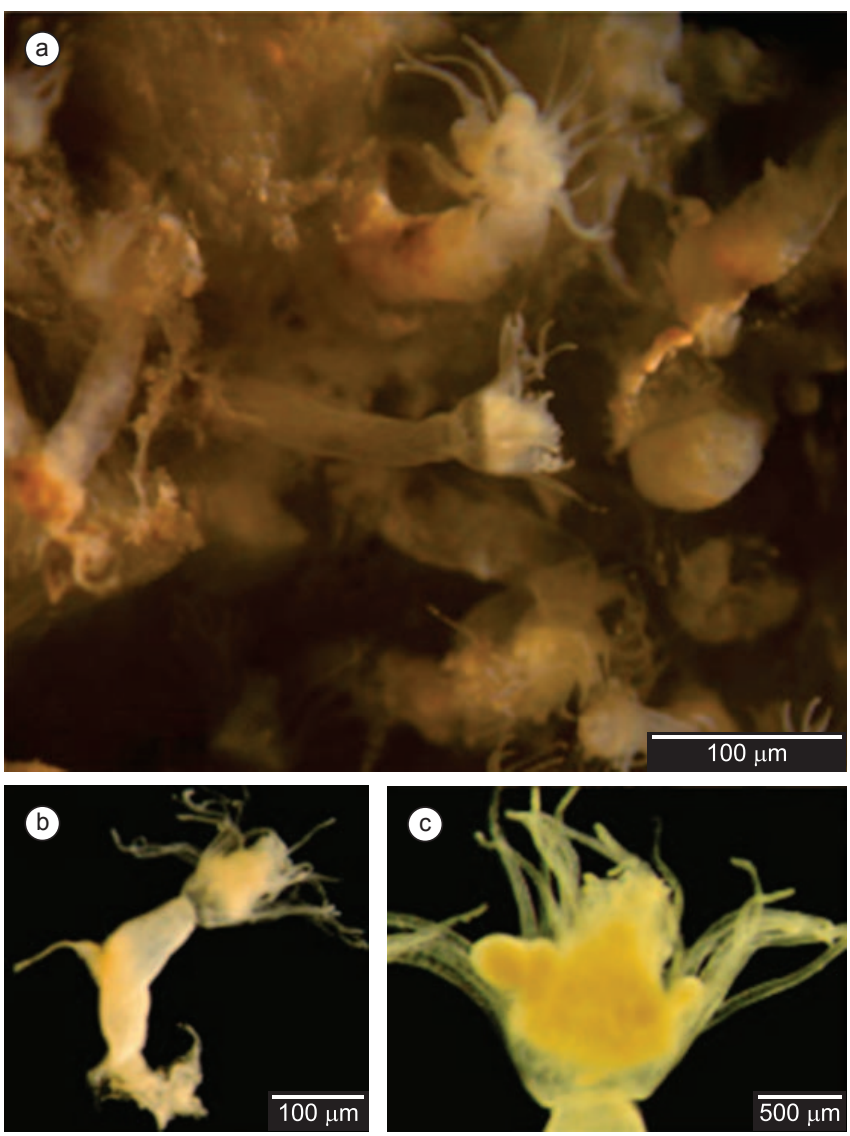

Figura 4. Zyzzyzus warreni Calder 1988. a) Diversos pólipos sobre esponja. b) Pólipo com seu sistema de fixação. c) Hidrante com gonóforos.

Figure 4. Zyzzyzus warreni Calder 1988. a) Several polyps on sponge. b) Polyp with anchoring system. c) Hydranth with gonophores. comprimento 800-1300 $\mu \mathrm{m}(\mathrm{n}=10)$, diâmetro máximo 740$1140 \mu \mathrm{m}(\mathrm{n}=10)$. Um verticilo de 12-19 $(\mathrm{n}=10)$ tentáculos orais filiformes, comprimento 400-750 $\mu \mathrm{m}(\mathrm{n}=20)$, diâmetro 48-79 $\mu \mathrm{m}(\mathrm{n}=20)$; um verticilo de 18-22 $(\mathrm{n}=10)$ tentáculos aborais filiformes, comprimento $1120-2000 \mu \mathrm{m}(\mathrm{n}=20)$, diâmetro 48-95 $\mu \mathrm{m}(\mathrm{n}=20)$. Hidrante maduro com 1-13 $(\mathrm{n}=10)$ gonóforos criptomedusoides acima da coroa de tentáculos aborais; gonóforos ovoides, comprimento 111,12-603,2 $\mu \mathrm{m}(\mathrm{n}=10)$, diâmetro máximo 79-397 $\mu \mathrm{m}(\mathrm{n}=10)$.

Comentários: esta espécie é conhecida como epizoica de porífero, mas foi reportada como epifítica (e.g., Hypnea cervicornis) e epizoica de outros cnidários (e.g., Eudendrium carneum e Zoanthus sp.) e ascídias (e.g., Clavelina oblonga) por Campos et al. (2007). Morfologia semelhante à dos materiais descritos por Campos et al. (2007) e Calder (1988).

Distribuição: Zyzzyzus warreni foi registrada para o Brasil nas regiões Nordeste, Sudeste e Sul, para os estados de Pernambuco, Alagoas, São Paulo, Paraná e Santa Catarina (Migotto et al. 2002, Campos et al. 2007, Oliveira et al., no prelo).

Ordem Filifera Kühn 1913

\section{FAMÍLIA BOUGAINVILLIIDAE Lütken 1850}

Bimeria vestita Wright 1859. (Figura 5a-b)

Bimeria vestita Wright 1859:109, pl.8, Figura 4; Millard 1975:95, Figura 32c-h; Calder 1988:21-23, Figuras 17-18a-b; Hirohito 1988:94-96, Figuras 33d-f, 34a; Migotto 1996:9-10, Figura 2a-b; Kelmo \& Santa-Isabel 1998:65-66, Figura 6; Marques et al. 2000:322324, Figuras 1-3; 2006:74-75; Shimabukuro et al. 2006:4-5.

[Sinonímia mais completa em Marques et al. 2000:322]

Material: Praia da Tainha, gonóforos ausentes, sobre briozoário, 31.XII.2002, A.C. Marques col. (MZUSP 4043).

Descrição: colônias estoloniais ou eretas, altura 0,6-1,3 mm $(\mathrm{n}=10)$, surgindo diretamente da hidrorriza. Hidrorriza tortuosa e ramificada, diâmetro 32-79 $\mu \mathrm{m}(\mathrm{n}=10)$. Colônias eretas pouco ramificadas. Hidrocaule monossifônico, comprimento 315-1050 $\mu \mathrm{m}(\mathrm{n}=10)$, diâmetro 55-70 $\mu \mathrm{m}(\mathrm{n}=10)$. Perissarco incrustrado com sedimento, com anelações basais e medianas, formando uma pseudo-hidroteca ao redor do hidrante e base do hipostômio, estendendo-se como uma estrutura tubular ao redor da base dos tentáculos. Um verticilo de 10-19 $(\mathrm{n}=10)$ tentáculos filiformes, comprimento 50-235 $\mu \mathrm{m}(\mathrm{n}=20)$, diâmetro
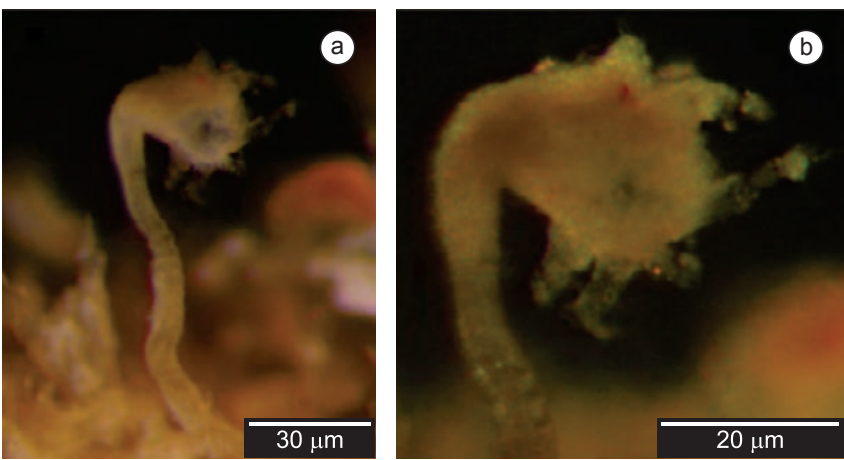

Figura 5. Bimeria vestita Wright 1859. a) Aspecto geral do pólipo. b) Detalhe do hidrante com tentáculos envoltos por pseudo-hidroteca.

Figure 5. Bimeria vestita Wright 1859. a) General aspect of the polyp. b) Detail of hydranth and tentacles with a pseudohydrotheca. 
16-48 $\mu \mathrm{m}(\mathrm{n}=20)$ ao redor de hidrante vasiforme, comprimento 174-349 $\mu \mathrm{m}(\mathrm{n}=10)$, diâmetro 79-179 $\mu \mathrm{m}(\mathrm{n}=10)$; hipostômio cônico. Gonóforos não observados.

Comentários: maior parte da colônia com crescimento estolonial e quase sem ramificações. Hidrantes contraídos, alguns sem tentáculos. Descrição geral semelhante à de Marques et al. (2000).

Distribuição: Bimeria vestita foi registrada para o Brasil nas regiões Nordeste e Sudeste, para os estados do Ceará e para a área incluída entre os estados de Alagoas e São Paulo (Migotto et al. 2002, Marques \& Migotto 2003, Grohmann 2006, Marques et al. 2006, Oliveira et al. 2006, Shimabukuro et al. 2006, Oliveira \& Marques 2007, Oliveira et al., no prelo). Este é o primeiro registro para a região sul e para o estado de Santa Catarina.

Bougainvillia muscus (Allman 1863). (Figura 6a-b)

Eudendrium ramosum; van Beneden 1844:56-58, pl.4, Figuras 1-13.

Perigonymus muscus Allman 1863:12.

Bougainvillia ramosa; Vannucci 1957:53-55; Vannucci \& Rees 1961:82-84; Goy 1979:271-272, Figura 6 [medusa].

Bougainvillia muscus; Calder 1988:24-28, Figuras 19a-c, 20a-e.

[Sinonímia mais completa em Calder 1988:24-25]

Material: Praia de Quatro Ilhas, gonóforos ausentes, sobre Eudendrium carneum, 1-2 m, 28.XII.2002, A.C. Marques col. (MZUSP 4042).

Descrição: colônias estoloniais, monossifônicas, altura 0,4$1,2 \mathrm{~mm}(\mathrm{n}=10)$, surgindo diretamente de hidrorriza tortuosa e ramificada, diâmetro 32-95 $\mu \mathrm{m}(\mathrm{n}=10)$. Pedículos, comprimento 200-825 $\mu \mathrm{m}(\mathrm{n}=10)$, diâmetro 40-75 $\mu \mathrm{m}(\mathrm{n}=10)$, com perissarco liso ou levemente ondulado, incrustrado com partículas de detritos; pseudo-hidroteca estendendo-se até base do hidrante ou base dos tentáculos. Hidrante cilíndrico, comprimento 205$370 \mu \mathrm{m}(\mathrm{n}=10)$, diâmetro 80-150 $\mu \mathrm{m}(\mathrm{n}=10)$, com um verticilo de 4-12 $(\mathrm{n}=10)$ tentáculos filiformes, comprimento 95-200 $\mu \mathrm{m}$ $(\mathrm{n}=20)$, diâmetro $16-48 \mu \mathrm{m}(\mathrm{n}=20)$ ao redor de hipostômio cônico. Gonóforos não observados.

Comentários: Calder (1988:26) descreve colônias de B. muscus como "initially stolonal, later erect". O material encontrado, embora em pouca quantidade, apresenta descrição geral semelhante à de Calder (1988) e, possivelmente, está em seu estado inicial de desenvolvimento, já que não possui ramificações e seu crescimento é predominantemente estolonial.
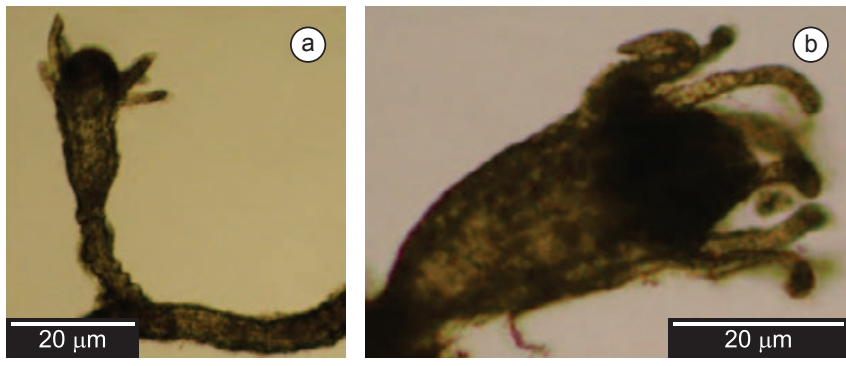

Figura 6. Bougainvillia muscus (Allman 1863). a) Aspecto geral do pólipo com pedículo. b) Detalhe do hidrante com base dos tentáculos envolta por pseudo-hidroteca.

Figure 6. Bougainvillia muscus (Allman 1863). a) General aspect of the polyp with pedicel. b) Detail of hydranth with base of the tentacles involved by a pseudohydrotheca.
Distribuição: o pólipo de Bougainvillia muscus foi registrado para o Brasil nas regiões Nordeste e Sul, para os estados de Alagoas, Paraná e Santa Catarina (Vannucci \& Rees 1961, Oliveira et al., no prelo).

\section{FAMÍLIA EUDENDRIIDAE L. Agassiz 1862}

Eudendrium carneum Clarke 1882. (Figura 7a-d)

Eudendrium carneum Clarke 1882:137, pl. 7, Figuras 10-17; Vannucci 1954:101-104, pl. 1, Figuras 1-9, pl. 2, Figura 8, pl. 4, Figuras 2-5; Millard 1975:82-84, Figura 28a-h; Calder 1988:4345, Figuras 33, 34a-d, 35a-b; Kelmo \& Santa-Isabel 1998:67-68, Figura 8; Marques 2001:350-361, Figuras 14-22; Marques et al. 2006:76-77; Shimabukuro et al. 2006: 6-8, Figuras 3-6.

[Sinonímia mais completa em Marques 2001:350-351]

Material: Praia de Quatro Ilhas, gonóforos presentes (fêmea), sobre rocha, 1-2 m, 28.XII.2002, A.C. Marques col. (MZUSP 4039). Praia da Sepultura, gonóforos presentes (fêmea), sobre rocha, 0-1 m, 29.XII.2002, A.C. Marques col. (MZUSP 4040). Praia da Tainha, gonóforos presentes (macho), sobre rocha e briozoário, 31.XII.2002, A.C. Marques col. (MZUSP 4041). Praia de Bombas, gonóforos ausentes, sobre rocha, 0-1 m, 14.XI.2005, V. Shimabukuro col. (MZUSP 4072).

Descrição: colônias com até $80 \mathrm{~mm}$ de altura $(\mathrm{n}=10)$, dioicas, arbustivas, ramos principais surgindo da hidrorriza, diâmetro 190-317 $\mu \mathrm{m}(\mathrm{n}=10)$. Colônias levemente polissifônicas na base, algumas mais polissifônicas da região basal até mediana; pouco a intensamente ramificadas, ramos até quinta ordem, dispostos radialmente ou em único plano, sem padrão de ramificação definido. Perissarco do ramo principal mais espesso, diâmetro
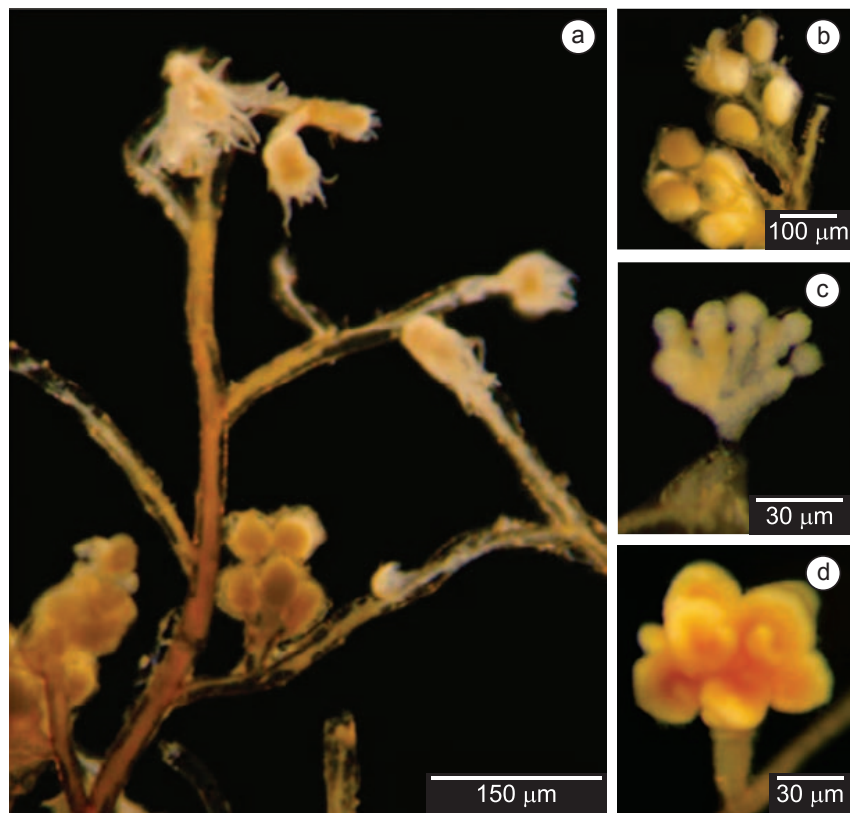

Figura 7. Eudendrium carneum Clarke 1882. a) Colônia com blastótilos femininos. b) Blastóstilo com gonóforo feminino maduro. c) Blastóstilo com gonóforos femininos imaturos com espádice bifurcado. d) Blastóstilo com gonóforos masculinos.

Figure 7. Eudendrium carneum Clarke 1882. a) Colony with female blastostyles. b) Blastostyle with mature female gonophores. c) Forked spadix blastostyle with immature female gonophores. d) Blastostyle with male gonophores. 
190-2301 $\mu \mathrm{m}(\mathrm{n}=10)$, coloração castanho-escuro na base, mais delgado e castanho-claro apicalmente (material fixado). Anelações espaçadas no ramo principal; até nove anelações ou ondulações na base dos pedículos e ramos. Hidrantes, comprimento 361-782 $\mu \mathrm{m}$ $(\mathrm{n}=10)$, diâmetro 179-434 $\mu \mathrm{m}(\mathrm{n}=10)$, com verticilo único de 12-27 ( $\mathrm{n}=10)$ tentáculos filiformes ao redor de hipostômio cônico (material fixado). Gonóforos surgindo no corpo do hidrante. Blastóstilos masculinos com 13-19 ( $\mathrm{n}=10)$ esporossacos formados por 2-3 câmaras $(n=10)$, diâmetro 95-126 $\mu \mathrm{m}(\mathrm{n}=10)$, com redução total do hipostômio e tentáculos desde início do desenvolvimento. Blastóstilos femininos com espádice bifurcado, curvo, sobre ovócito único; dois a nove ovócitos imaturos $(\mathrm{n}=10)$, diâmetro 126-333 $\mu \mathrm{m}(\mathrm{n}=10)$, dispostos em coroa ao redor da coluna do hidrante; blastóstilos maduros com redução dos tentáculos, hipostômio e espádice; ovos dispostos em cachos irregulares, espessados por perissarco exceto por duas fenestras de perissarco menos espesso; blastóstilos também envoltos por perissarco. Nematocistos de dois tipos: anizorrizas heterótricos grandes, cápsulas elipsoides, comprimento 20-31 $\mu \mathrm{m}(\mathrm{n}=10)$, diâmetro 9-18 $\mu \mathrm{m}(\mathrm{n}=10)$; euritelos microbásicos pequenos, cápsula ovoide, comprimento 8-11 $\mu \mathrm{m}(\mathrm{n}=10)$.

Comentários: algumas colônias não estão férteis; há uma colônia com gonóforos femininos em todos os pedículos e nenhum hidrante; outra sem hidrantes ou gonóforos. Material semelhante à descrição de Marques (2001).

Distribuição: Eudendrium carneum foi registrada para o Brasil nas regiões Nordeste, Sudeste e Sul, para a área incluída entre os estados do Ceará e Santa Catarina (Migotto et al. 2002, Marques \& Migotto 2003, Grohmann 2006, Marques et al. 2006, Shimabukuro et al. 2006, Amaral et al. 2009, Oliveira et al., no prelo).

Subclasse Leptothecata Cornelius 1992

Ordem Conica Broch 1910

FAMÍLIA AGLAOPHENIIDAE Marktanner-Turneretscher 1890

Aglaophenia latecarinata Allman 1877. (Figura 8a-d)

Aglaophenia perpusilla Allman 1877:48-49, pl. XXIX, Figuras 5-7.

Aglaophenia late-carinata Allman 1877:56 [grafia original incorreta]; Vannucci Mendes 1946:586-587, est. 7, Figuras 60-64, 68-69; Vannucci 1949:255-256; Maÿal 1983:8, Figura 13.

Aglaophenia perforata; Vannucci 1951:89-90, t. 3, Figuras 21-23.

Aglaophenia latecarinata; Millard 1975:409-411, Figura 128d-f; Migotto 1996:38-40, Figura 8a-d; Calder 1997:55-59, Figura 17a-f; Marques et al. 2006:83-84.

[Sinonímia mais completa em Calder 1997:55]

Material: Ponta das Garoupas, sem córbula, sobre Sargassum cymosum, 4 m, 16.X.1993, M.A. Haddad col. (MZUSP 4001); sem córbula, 1,5-3 m, 11.I.1994 (MZUSP 4002); sem córbula, 0-1, 5 m, 13.VIII.1994 (MZUSP 4003); sem córbula, 0-1,5 m, 28.V.1994 (MZUSP 4004). Praia de Quatro Ilhas, com córbula, sobre alga, 1-2 m, 28.XII.2002, A.C. Marques col. (MZUSP 4046). Praia da Sepultura, com córbula, sobre alga, 0-1 m, 29.XII.2002, A.C. Marques col. (MZUSP 4048). Praia da Tainha, com córbula, sobre rocha, 31.XII.2002, A.C. Marques col. (MZUSP 4050). Praia de Bombas, com córbula, sobre Sargassum sp., 0-1 m, 13.XI.2005, V. Shimabukuro col. (MZUSP 4073).
Descrição: colônias com até $35 \mathrm{~mm}$ de altura $(\mathrm{n}=10)$, eretas, surgindo diretamente da hidrorriza, diâmetro 90-349 $\mu \mathrm{m}(\mathrm{n}=10)$; hidrocaule monossifônico, não ramificado, coloração marrom (material fixado), diâmetro 158-396 $\mu \mathrm{m}(\mathrm{n}=10)$. Perissarco espessado na região proximal, estreitando-se progressivamente distalmente. Parte não segmentada do hidrocaule, comprimento 873-9206 $\mu \mathrm{m}(\mathrm{n}=10)$, com uma fileira de nematotecas frontais, separada do restante do hidrocaule por dois nós oblíquos. Parte distal do hidrocaule dividida em entrenós por nós oblíquos. Cada entrenó com uma apófise com um hidrocládio de coloração branca (material fixado). Hidrocládios, comprimento 1047-3063 $\mu \mathrm{m}$ $(n=10)$, dispostos alternadamente, não ramificados, divididos em entrenós por nós transversais. Cada entrenó apresenta uma hidroteca, uma nematoteca mediana inferior, duas nematotecas laterais e dois septos internos: um no nível do septo intratecal, outro na base das nematotecas laterais. Maior parte da parede da hidroteca adnata ao entrenó do hidrocládio, com pequena porção distal livre. Parede adcaulinar convexa; parede abcaulinar convexa basalmente, levemente côncava do nível do septo intratecal até margem hidrotecal; comprimento da hidroteca 190-360 $\mu \mathrm{m}(\mathrm{n}=10)$; diâmetro da borda 140-185 $\mu \mathrm{m}(\mathrm{n}=10)$. Margem com nove cúspides, separadas por incisões em forma de 'U', carena abcaulinar mesial desde base da nematoteca mediana inferior até margem da hidroteca, septo transversal interno aparentemente divide hidroteca em duas câmaras, uma proximal mais curta, outra distal mais longa. Nematoteca
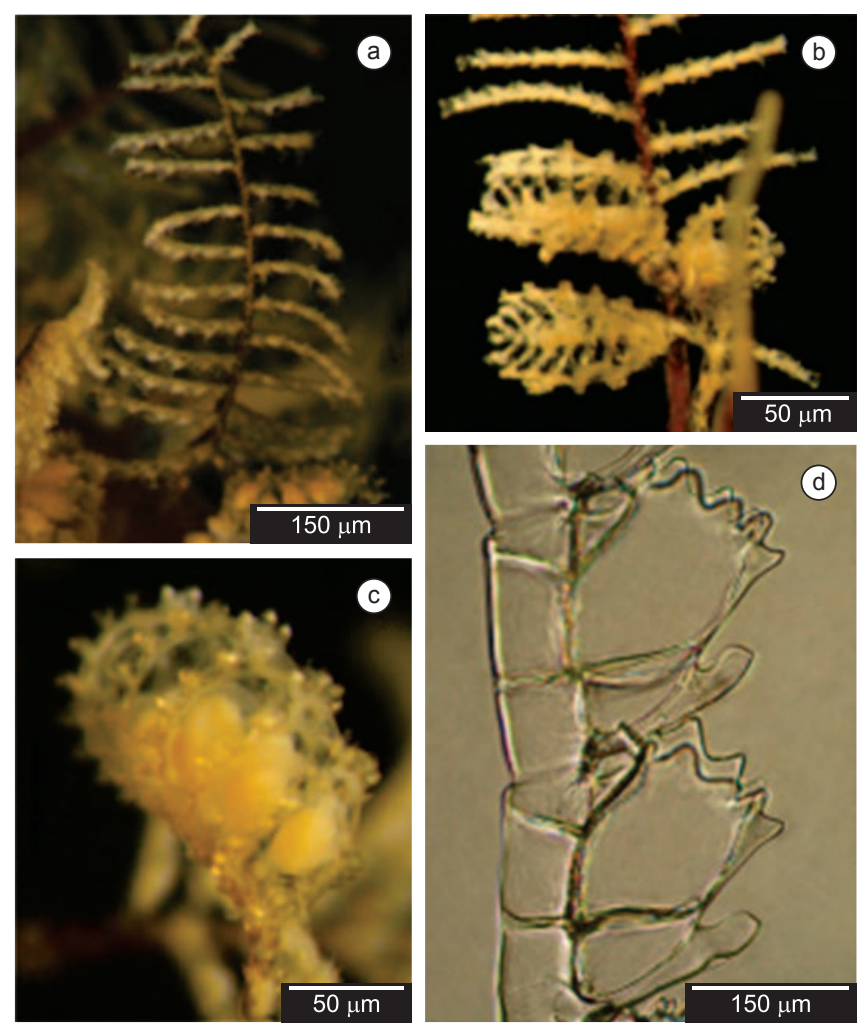

Figura 8. Aglaophenia latecarinata Allman 1877. a) Colônia fértil. b) Colônia com córbulas abertas. c) Aspecto geral da córbula. d) Hidroteca em vista lateral, sem o cenossarco.

Figure 8. Aglaophenia latecarinata Allman 1877. a) Fertile colony. b) Colony with open corbules. c) General aspect of corbule. d) Hydrotheca in lateral view, without coenosarc. 
mediana inferior, comprimento 165-265 $\mu \mathrm{m}(\mathrm{n}=10)$, diâmetro 20-30 $\mu \mathrm{m}(\mathrm{n}=10)$, projeta-se além do nível do septo intratecal, maior parte adnata à base da hidroteca, parte distal livre mais curta. Nematotecas laterais, comprimento 70-170 $\mu \mathrm{m}(\mathrm{n}=10)$, diâmetro 15-35 $\mu \mathrm{m}(\mathrm{n}=10)$, direcionadas para fora, atingindo borda hidrotecal. Região proximal do hidrocaule com uma a três córbulas, comprimento 1300-5555 $\mu \mathrm{m}(\mathrm{n}=10)$, diâmetro 793$1190 \mu \mathrm{m}(\mathrm{n}=10)$, cinco a oito pares de nematocládios $(\mathrm{n}=10)$ abrigando cinco a 10 nematotecas $(n=10)$ na superfície externa.

Comentários: colônias semelhantes à descrição de Migotto (1996).

Distribuição: Aglaophenia latecarinata foi registrada para o Brasil nas regiões Nordeste, Sudeste e Sul, para a área incluída entre os estados do Maranhão e Pernambuco, e entre a Bahia e Santa Catarina (Migotto et al. 2002, Grohmann 2006, Marques et al. 2006, Oliveira et al. 2006, Oliveira \& Marques 2007, Amaral et al. 2009, Oliveira et al., no prelo).

Macrorhynchia philippina Kirchenpauer 1872. (Figura 9a-d)

Macrorhynchia philippina Kirchenpauer 1872:19; Vannucci Mendes 1946:587-588, est. 6, Figura 71, est. 7, Figura 65; Vannucci 1949:256; 1954:118; Migotto 1996:40-42, Figura 8e-f; Calder 1997:66-69, Figura 21a-b.

Aglaophenia philippina Kirchenpauer 1872:45-46, pl. 1, Figura 26, pl. 2, Figura 26a-b, pl. 7, Figura 26, texto e Figura p. 17.
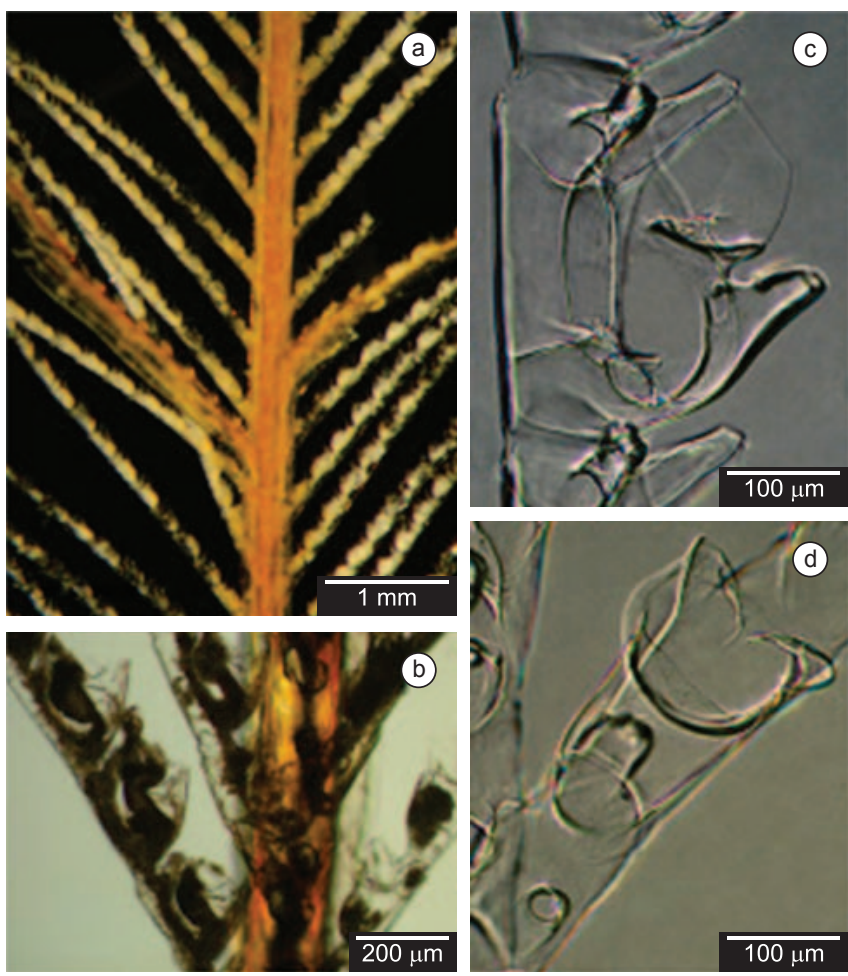

Figura 9. Macrorhynchia philippina Kirchenpauer 1872. a) Ramo principal e hidrocládios. b) Base dos hidrocládios com hidrotecas. c) Hidroteca em vista lateral e d) em vista oral.

Figure 9. Macrorhynchia philippina Kirchenpauer 1872. a) Main stem and hydrocladia. b) Basis of hydrocladia with hydrothecae. c) Hydrotheca in lateral view and d) oral view.
[Sinonímia mais completa em Calder 1997:66-67]

Material: Praia da Sepultura, gonóforos ausentes, sobre rocha, 0-1 m, 29.XII.2002, A.C. Marques col. (MZUSP 4047). Praia da Tainha, gonóforos ausentes, sobre rocha, 31.XII.2002, A.C. Marques col. (MZUSP 4049).

Descrição: colônias eretas com até $8 \mathrm{~mm}$ de altura $(\mathrm{n}=10)$, surgindo diretamente da hidrorriza, diâmetro 158-317 $\mu \mathrm{m}(\mathrm{n}=$ 10). Hidrocaule principal pinado ou bipinado, polissifônico, ramos terminais monossifônicos, diâmetro proximal 492$1000 \mu \mathrm{m}(\mathrm{n}=10)$, diâmetro distal 317-519 $\mu \mathrm{m}(\mathrm{n}=10)$. Parte polissifônica composta por eixo tubular principal com nematotecas e hidrocládios alternados, hidrocaules periféricos sem tecas e hidrocládios originando ramos laterais. Parte não segmentada do hidrocaule, comprimento1428-15396 $\mu \mathrm{m}(\mathrm{n}=10)$, com série de nematotecas frontais, separada da parte segmentada por nó oblíquo. Cada entrenó do hidrocaule com hidrocládio não ramificado sustentado por apófise com duas nematotecas, proximal e distal. Hidrocládios alternados, não ramificados, comprimento 2809-4984 $\mu \mathrm{m}(\mathrm{n}=10)$, divididos em entrenós por nós transversais. Cada entrenó, comprimento 245-315 $\mu \mathrm{m}$ ( $\mathrm{n}=10)$, diâmetro 50-115 $\mu \mathrm{m}(\mathrm{n}=10)$, com uma hidroteca, uma nematoteca mediana inferior, um par de nematotecas laterais, dois septos intranodais. Hidroteca, comprimento 175-315 $\mu \mathrm{m}$ ( $\mathrm{n}=10)$, diâmetro da borda $120-160 \mu \mathrm{m}(\mathrm{n}=10)$, com parede adcaulinar convexa, adnata ao entrenó do hidrocládio, parte distal livre. Parede abcaulinar convexa proximalmente, côncava distalmente abaixo da margem da hidroteca. Septo intratecal abcaulinar estende-se por mais da metade da cavidade intratecal, margem hidrotecal com três cúspides: duas laterais arredondadas, uma mesial menor que as outras. Nematoteca mediana inferior longa, tubular, levemente curva, estendendo-se além da margem hidrotecal, metade proximal adnata à parede abcaulinar hidrotecal até nível do septo intratecal, metade distal livre, comprimento 195-280 $\mu \mathrm{m}(\mathrm{n}=10)$, diâmetro da borda 20-30 $\mu \mathrm{m}(\mathrm{n}=10)$. Nematotecas laterais tubulares, adnatas à parede da hidroteca, porção distal livre, curvando-se levemente para além da margem hidrotecal, comprimento 110-165 $\mu \mathrm{m}(\mathrm{n}=10)$, diâmetro da borda 20-30 $\mu \mathrm{m}(\mathrm{n}=10)$. Partes reprodutivas não observadas.

Comentários: colônias semelhantes à descrição de Migotto (1996) e Calder (1997).

Distribuição: Macrorhynchia philippina foi registrada para o Brasil, nas regiões Nordeste, Sudeste e Sul, para os estados de Pernambuco, Alagoas e para a área incluída entre os estados da Bahia e Santa Catarina (Migotto et al. 2002, Oliveira et al. 2006, Oliveira \& Marques 2007, Oliveira et al., no prelo).

FAMÍLIA Haleciidae Hincks 1868

Halecium dyssymetrum Billard 1929. (Figuras 10a-b)

Halecium dyssymetrum Billard 1929:307, Figura 1c; Millard 1975:150, Figura 48h, j; Migotto 1996:32-34, Figura 7d-f.

Endothecium dyssymetrum Calder 1991:14-16, Figuras 6a-c, 7a-c.

Material: Ponta das Garoupas, gonóforos ausentes, sobre Sargassum cymosum, 4 m, 16.X.1993, M.A. Haddad col. (MZUSP 4018).

Descrição: colônias eretas, surgindo diretamente da hidrorriza, altura 2-3 mm $(n=4)$; diâmetro hidrorriza 111-222 $\mu \mathrm{m}(\mathrm{n}=10)$. Perissarco fino na região mediana, espessando-se na direção basal e hidrotecas. Hidrocaule monossifônico, não ramificado, geniculado, dividido em entrenós por nós transversais; comprimento entrenós 397-714 $\mu \mathrm{m}(\mathrm{n}=5)$, diâmetro no nível do nó 111-143 $\mu \mathrm{m}(\mathrm{n}=5)$; comprimento pedículo secundário 

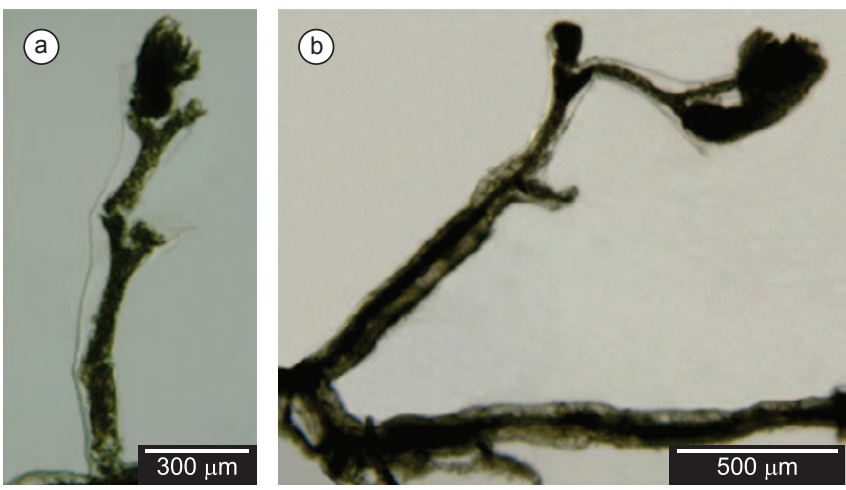

Figura 10. Halecium dyssymetrum Billard 1929. a) Ramo com pólipo terminal. b) Hidrante em hidroteca rasa.

Figure 10. Halecium dyssymetrum Billard 1929. a) Stem with terminal polyp. b) Hydranth in a shallow hydrotheca.

444-682 $\mu \mathrm{m}(\mathrm{n}=5)$; hidrotecas surgindo da apófise distal de cada entrenó; diâmetro da hidroteca ampliando distalmente, borda não evertida, diafragma espesso, evidente basalmente, anel de desmócitos abaixo do diafragma; hidroteca primária séssil, comprimento 317-206 $\mu \mathrm{m}(\mathrm{n}=5)$, diâmetro da borda 254-317 $\mu \mathrm{m}$ $(\mathrm{n}=5)$, diâmetro no nível do diafragma 127-159 $\mu \mathrm{m}(\mathrm{n}=5)$; hidroteca secundária pedicelada, comprimento 191-397 $\mu \mathrm{m}$ $(\mathrm{n}=5)$, diâmetro da borda 239-428 $\mu \mathrm{m}(\mathrm{n}=5)$, diâmetro no nível do diafragma 174-301 $\mu \mathrm{m}(\mathrm{n}=5)$. Hidrantes vasiformes (material fixado), longos e largos, com um verticilo de ca. 16-23 ( $n=5)$ tentáculos filiformes, comprimento 175-206 $\mu \mathrm{m}(\mathrm{n}=5)$, diâmetro 32-48 $\mu \mathrm{m}(\mathrm{n}=5)$. Gonotecas não observadas.

Comentários: Halecium dyssymetrum Billard 1929 pode ser distinguido de $H$. tenellum Hincks 1861 principalmente pelo maior comprimento de sua hidroteca, borda não evertida e hidrante largo, além da grande espessura do perissarco e diafragma, característica esta comumente usada como diagnóstico da espécie. Colônias semelhantes às descrições de Calder (1991) e Migotto (1996).

Distribuição: Halecium dyssymetrum foi registrado para o Brasil na região Sudeste e Sul, para os estados do Espírito Santo, São Paulo e Santa Catarina (Migotto et al. 2002, Oliveira et al. 2006, Oliveira \& Marques 2007, Oliveira et al., no prelo).

Halecium tenellum Hincks 1861. (Figura 11a-c)

Halecium tenellum Hincks 1861:252, pl.6, Figuras 1-4; Millard 1975:156-157, Figura 50f-1; Calder 1991:22-24, Figura 14; Cornelius 1995a:296-297, Figura 69a-e; Migotto 1996:34-35, fig 6h.

Material: Praia de Quatro Ilhas, gonóforos ausentes, sobre rocha e Eudendrium carneum, 1-2 m, 28.XII.2002, A.C. Marques col. (MZUSP 4059). Praia da Tainha, gonóforos ausentes, sobre porífero, 31.XII.2002, A.C. Marques col. (MZUSP 4060).

Descrição: colônias monossifônicas, com até $1,5 \mathrm{~mm}$ de altura $(n=10)$, majoritariamente estolonial, poucas partes eretas surgindo de hidrorriza, diâmetro 50-110 $\mu \mathrm{m}(\mathrm{n}=10)$. Partes eretas pouco ramificadas, com apenas um entrenó e uma apófise. Hidrotecas rasas, com até cinco renovações; hidroteca primária séssil, comprimento 230-1050 $\mu \mathrm{m}(\mathrm{n}=10)$, diâmetro da borda 100-240 $\mu \mathrm{m}(\mathrm{n}=10)$, diâmetro no nível do diafragma 60-180 $\mu \mathrm{m}$ $(\mathrm{n}=10)$; hidroteca secundária pedicelada, comprimento 20-50 $\mu \mathrm{m}$ $(\mathrm{n}=10)$, diâmetro da borda 100-190 $\mu \mathrm{m}(\mathrm{n}=10)$, diâmetro no nível do diafragma 60-90 $\mu \mathrm{m}(\mathrm{n}=10)$. Diafragma demarcado
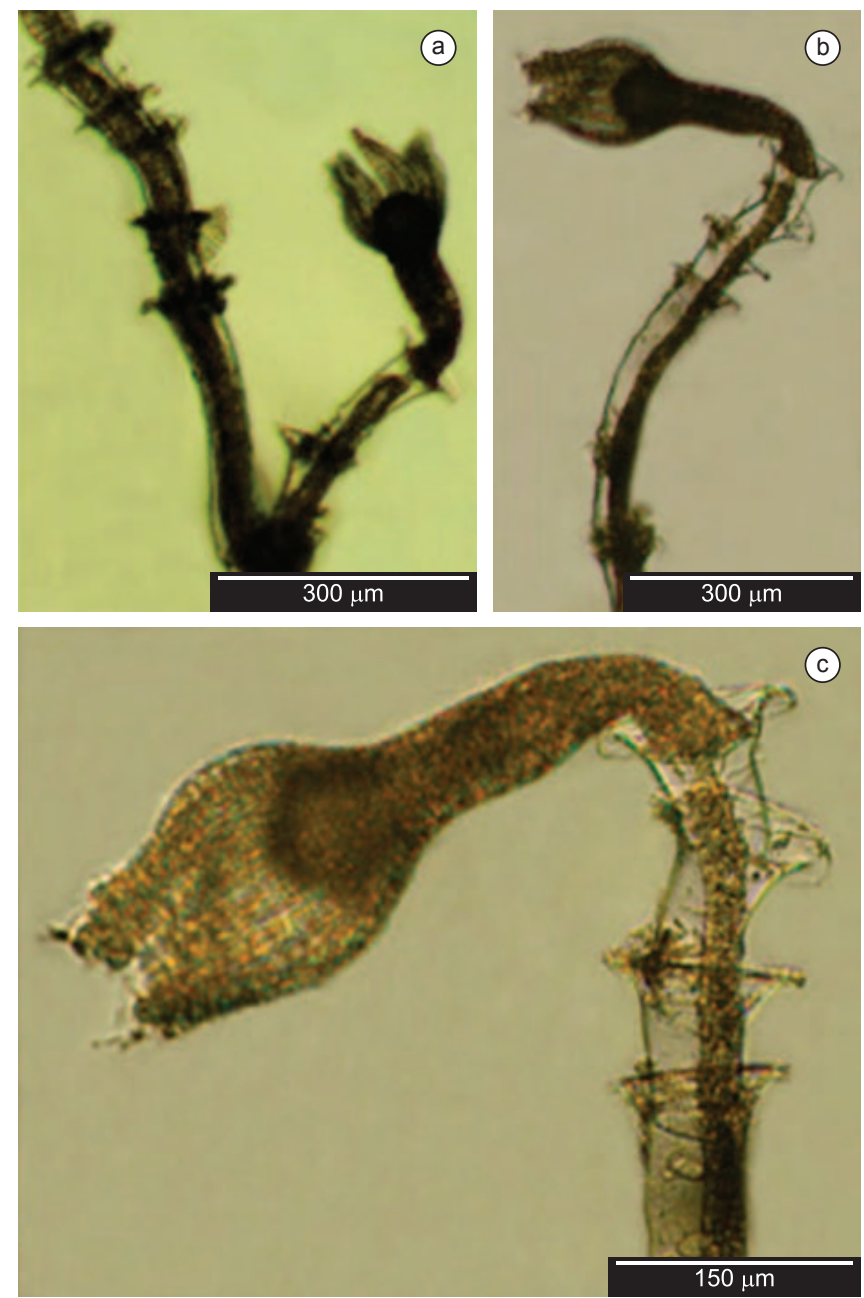

Figura 11. Halecium tenellum Hincks 1861. a) Colônia com ramificação e renovações da hidroteca. b) Hidrantóforo com sucessivas renovações e hidrante terminal. c) Detalhe do hidrante.

Figure 11. Halecium tenellum Hincks 1861. a) Colony with branch and hydrotheca renovation. b) Hydrantophore with successive renovations and terminal hydranth. c) Hydranth detail.

basalmente por anel de desmócitos. Borda hidrotecal lisa, margem evertida. Hidrantes longos, comprimento 165-5335 $\mu \mathrm{m}$

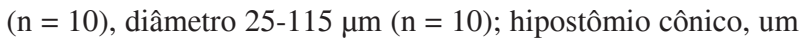
verticilo de ca. $10-25$ tentáculos filiformes $(n=10)$. Gonotecas não observadas.

Comentários: as colônias da praia da Tainha estão danificadas, pouco desenvolvidas e não apresentam hidrotecas secundárias. Material semelhante à descrição de Calder (1991) e de Migotto (1996).

Distribuição: Halecium tenellum foi registrado para o Brasil nas regiões Nordeste, Sudeste e Sul, para os estados de Pernambuco, São Paulo e Santa Catarina (Migotto et al. 2002, Oliveira et al. 2006, Oliveira \& Marques 2007, Oliveira et al., no prelo).

\section{FAMÍLIA HEBELLIDAE Fraser 1912}

Hebella scandens (Bale 1888). (Figura 12a-d)

Lafoea scandens Bale 1888:758-759, pl. 13, Figuras 16-19. 
Hebella scandens; Vannucci 1949:236-237, pl. 2, Figuras 22-23; 1950:85; Millard 1975:182-184, Figura 60f-g; Migotto 1996:26-27, Figura 6a-b; Marques et al. 2006:85.

Hebellopsis sinuosa Vannucci 1949:237-238, pl. 2, Figura 24.

Hebellopsis besnardi Vannucci 1950:85, pl.1, Figura 3.

Hebellopsis scandens; Calder 1991:43-45, Figura 27.

[Sinonímia mais completa em Calder 1991:43]

Material: Praia de Bombas, gonóforos ausentes, sobre Sertularia marginata, 0-1 m, 13.XI.2005, V. Shimabukuro col. (MZUSP 4080).

Descrição: colônias estoloniais, hidrorriza crescendo sobre o hidrocaule e hidrocládios de Sertularia marginata; diâmetro hidrorriza 32-79 $\mu \mathrm{m}(\mathrm{n}=10)$. Hidrotecas pediceladas surgindo da hidrorriza entre hidrotecas de $S$. marginata. Pedículos lisos, comprimento 32-64 $\mu \mathrm{m}(\mathrm{n}=10)$, diâmetro 32-79 $\mu \mathrm{m}(\mathrm{n}=10)$. Hidrotecas cilíndricas, lisas, ligeiramente curvas, altura 254 $476 \mu \mathrm{m}(\mathrm{n}=10)$, diâmetro 159-302 $\mu \mathrm{m}(\mathrm{n}=10)$. Borda hidrotecal
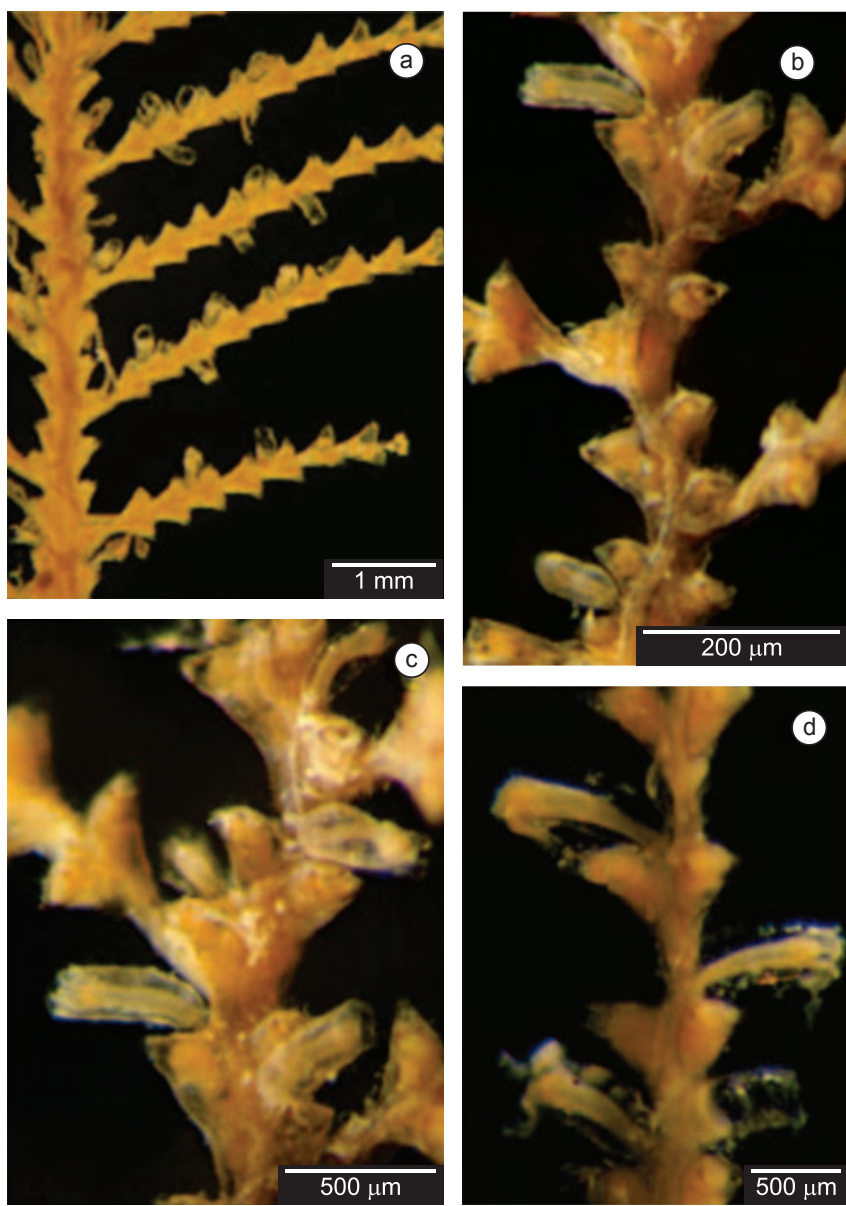

Figura 12. Hebella scandens (Bale 1888). a) Colônia epizóica de Sertularia marginata (Kirchenpauer 1864). b) Detalhe da hidrorriza e hidrotecas sobre a colônia de S. marginata (Kirchenpauer 1864). c, d) Hidrotecas com hidrantes.

Figure 12. Hebella scandens (Bale 1888). a) Epizoic colony of Sertularia marginata (Kirchenpauer 1864). b) Detail of hydrorhiza and hydrothecae on S. marginata (Kirchenpauer 1864). c, d) Hydrothecae with hydranths. lisa, algumas levemente evertidas, diâmetro 95-302 $\mu \mathrm{m}(\mathrm{n}=10)$. Gonotecas não observadas.

Comentários: material semelhante à descrição de Calder (1991) e Migotto (1996).

Distribuição: o pólipo de Hebella scandens foi registrado para o Brasil nas regiões Nordeste, Sudeste e Sul, para o Ceará e a área incluída entre os estados do Espírito Santo e Santa Catarina (Migotto et al. 2002, Marques et al. 2006, Oliveira et al., no prelo)

FAMÍLIA KIRCHENPAUERIIDAE Stechow 1921

Pycnotheca mirabilis (Allman 1883). (Figura 13 a-f)

Dyplocheilus mirabilis Allman 1883:49, pl. 8, Figuras 4-7.

Pycnotheca mirabilis; Millard 1975:377-379, Figura 120d-g; Hirohito 1995:256-258, Figura 86a-e.

Kirchenpaueria mirabilis f. robusta; Vannucci Mendes 1946:574575, est. 4, Figura 44, est. 5, Figura 45, est. 7, Figura 66; Vannucci 1950:88-89.

Material: Ponta das Garoupas, gonóforos ausentes, sobre Sargassum cymosum, 4 m, 16.X.1993, M.A. Haddad col. (MZUSP 4019). Praia da Tainha, gonóforos ausentes, sobre alga, 31.XII.2002, A.C. Marques col. (MZUSP 4061).
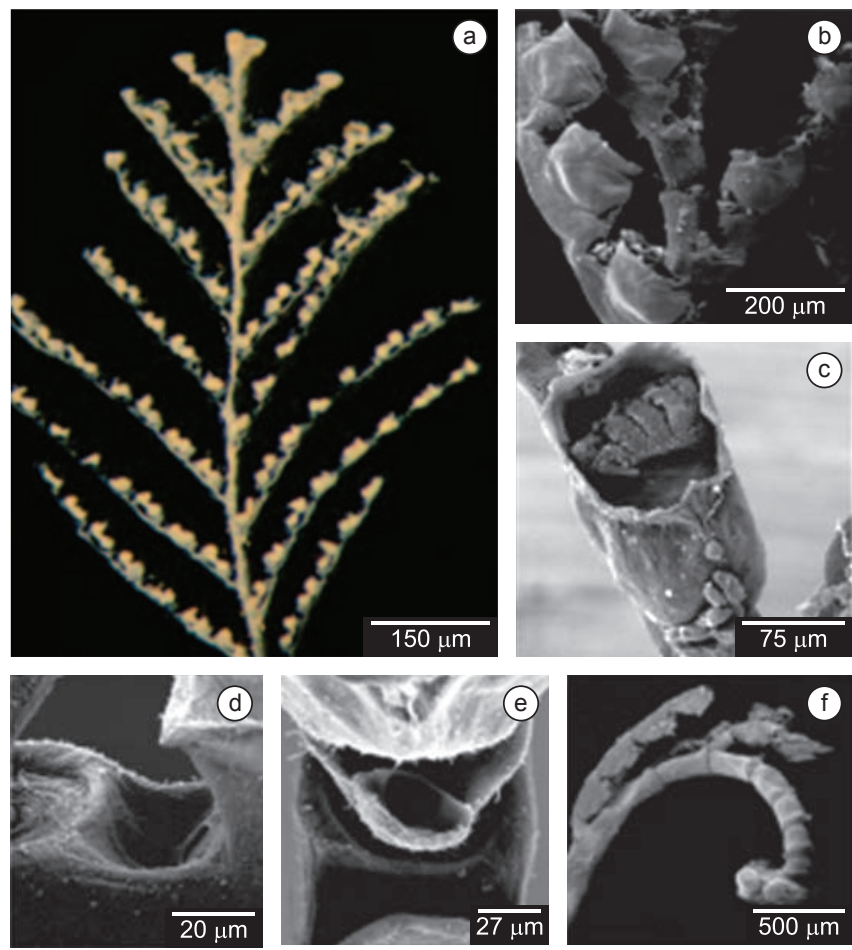

Figura 13. Pycnotheca mirabilis (Allman 1888). a) Aspecto geral da porção distal do pólipo. b-f) Microscopia eletrônica de varredura. b) Hidrocaule e hidrocládios em vista lateral. c) Hidroteca em vista oral com septo intratecal. d) Sarcóstilo mediano da hidroteca em vista lateral. e) Nematoteca mediana inferior da hidroteca em vista oral. f) Detalhe da estrutura distal da colônia.

Figure 13. Pycnotheca mirabilis (Allman 1888). a) General aspect of distal portion of polyp. b-f) Scanning electron microscopy. b) Hydrocaulus and hydrocladia in lateral view. c) Hydrotheca in oral view with intrathecal septum. d) Median sarcostyle of hydrotheca in lateral view. e) Inferior median nemathoteca of hydrotheca in oral view. f) Detail of the distal structure of the colony. 
Descrição: colônias monossifônicas, pinadas, altura 9-19 $\mathrm{mm}(\mathrm{n}=10)$, surgindo diretamente da hidrorriza; diâmetro da hidrorriza 127-222 $\mu \mathrm{m}(\mathrm{n}=10)$. Hidrocaule dividido por nós transversais na região proximal e nós oblíquos nas regiões mediana e distal, resultando em entrenós com comprimento 365-1047 $\mu \mathrm{m}(\mathrm{n}=20)$ diâmetro 142-238 $\mu \mathrm{m}(\mathrm{n}=20)$; entrenós com uma nematoteca na região distal e uma a duas apófises, comprimento $130-270 \mu \mathrm{m}(\mathrm{n}=10)$; região distal da apófise com um 'mamelon'. Região axilar do hidrocládio com uma nematoteca. Parte proximal do hidrocaule sem hidrocládios, comprimento 666-4920 $\mu \mathrm{m}(\mathrm{n}=10)$. Hidrocládios alternados, comprimento 2000-3200 $\mu \mathrm{m}(\mathrm{n}=10)$, com entrenós regulares, comprimento 357-562 $\mu \mathrm{m}(\mathrm{n}=10)$, diâmetro 43-67 $\mu \mathrm{m}(\mathrm{n}=10)$, delimitados por nós oblíquos. Cada hidrocládio com cinco a oito $(\mathrm{n}=10)$ hidrotecas; cada entrenó do hidrocládio com uma hidroteca com uma nematoteca mediana inferior e um sarcóstilo mediano nu localizado em depressão do perissarco atrás da parte livre da parede adcaulinar. Hidroteca em forma de taça ocupando maior parte do entrenó, mais da metade da parede adcaulinar adnata ao hidrocládio, borda lisa. Parte adnata da parede adcaulinar da hidroteca com comprimento 258-325 $\mu \mathrm{m}$ $(\mathrm{n}=10)$, parte livre da parede adcaulinar com comprimento 55$89 \mu \mathrm{m}(\mathrm{n}=10)$, comprimento abcaulinar 167-210 $\mu \mathrm{m}(\mathrm{n}=10)$. Diâmetro da borda/margem hidrotecal 199-257 $\mu \mathrm{m}(\mathrm{n}=10)$. Septo intratecal projetando-se na parte distal da parede abcaulinar para interior do lúmen hidrotecal. Nematoteca mediana inferior bicameral, em formato de escudo, comprimento 9-19 $\mu \mathrm{m}(\mathrm{n}=10)$, diâmetro proximal 4-10 $\mu \mathrm{m}(\mathrm{n}=10)$, diâmetro distal 3-7 $\mu \mathrm{m}$ $(n=10)$. Gonotecas não observadas.

Comentários: material semelhante à descrição de Hirohito (1995). Não há um padrão homogêneo de variação do tamanho dos entrenós, ou seja, algumas colônias têm entrenós maiores na base (com dois hidrocládios) e no ápice da colônia, outras com entrenós menores (praticamente do mesmo tamanho e com um hidrocládio) e outras, ainda, com entrenós apicais maiores (dois hidrocládios) e basais menores (um hidrocládio). Em algumas colônias os entrenós do ápice vão diminuindo em seu tamanho devido à presença de uma estrutura apical na forma semelhante à de um trevo de quatro folhas, a qual, segundo Vannucci Mendes (1946:575), relaciona-se a uma "reprodução estolonífera do caule".

Distribuição: Pycnotheca mirabilis foi registrada para o Brasil nas regiões Nordeste, Sudeste e Sul, para os estados da Paraíba, Espírito Santo, Rio de Janeiro, São Paulo e Santa Catarina (Migotto et al. 2002, Grohmann et al. 2003, Oliveira et al., no prelo).

\section{FAMÍLIA LAFOEIDAE A. Agassiz 1865}

Filellum sp. (Figura 14 a-e)

Material: Ponta das Garoupas, copínia ausente, sobre Sargassum cymosum, 1,5-3 m, 11.I.1994, M.A. Haddad col. (MZUSP 4020). Praia de Quatro Ilhas, copínia ausente, sobre Eudendrium carneum, 1-2 m, 28.XII.2002, A.C. Marques col. (MZUSP 4062).

Descrição: colônias estoloniais. Hidroteca séssil, surgindo da hidrorriza, maior parte do comprimento adnato ao substrato. Parte adnata da hidroteca paralela à hidrorriza, com rugosidades transversais, comprimento $135-2890 \mu \mathrm{m}(\mathrm{n}=10)$. Parte livre da hidroteca perpendicular à adnata, tubular, comprimento 115-249 $\mu \mathrm{m}(\mathrm{n}=10)$. Abertura hidrotecal circular, borda lisa, levemente evertida, diâmetro da borda 63-95 $\mu \mathrm{m}(\mathrm{n}=10)$. Hidrante com comprimento 25-55 $\mu \mathrm{m}(\mathrm{n}=10)$, diâmetro 35-
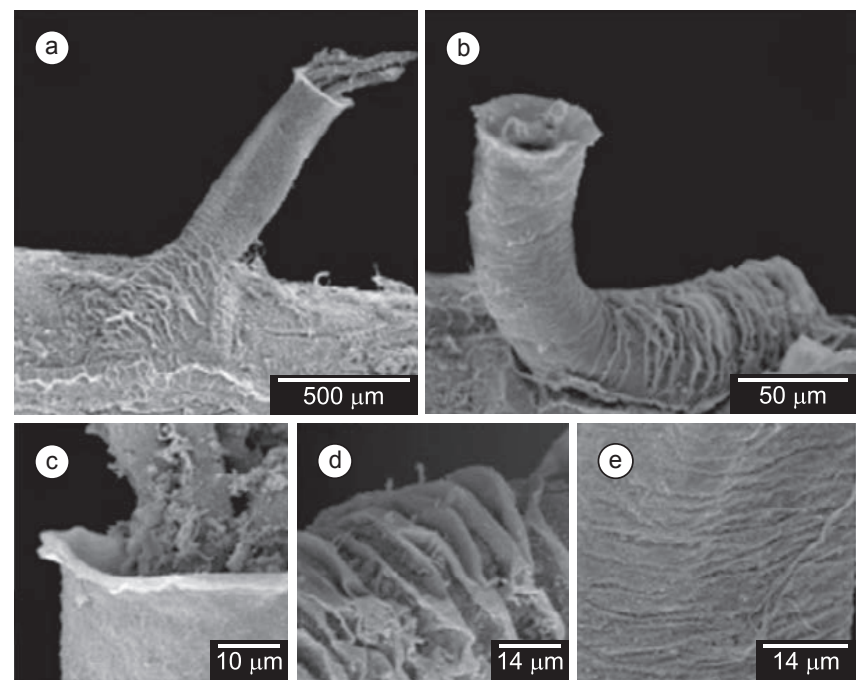

Figura 14. Microscopia eletrônica de varredura de Filellum sp. a) e b) Hidrotecas com hidrantes. c) Borda da hidroteca. d) Detalhe das estrias da parte adnata da hidroteca. e) das estrias da parte livre da hidroteca.

Figure 14. Scanning electron microscopy of Filellum sp. a) and b) Hydrothecae with hydranths. c) Margin of hydrotheca. d) Striae details of the adnate part of hydrotheca. e) of the free part of hydrotheca.

$60 \mu \mathrm{m}(\mathrm{n}=10)$, quatro a $10(\mathrm{n}=10)$ tentáculos filiformes em verticilo único. Gonotecas (copínias) não observadas.

Comentários: colônias epizoicas de Eudendrium carneum ou epifíticas de Sargassum cymosum. Devido às rugosidades da parte adnata da hidroteca, o trofossomo do material estudado é semelhante aos de Filellum serratum (Clarke 1879), F. antarcticum (Hartlaub 1904), F. magnificum Peña Cantero, Svoboda \& Vervoort 2004 e F. nitidum Watson 2005 (ver Marques et al., 2011). Os trofossomos dessas espécies são morfologicamente indistinguíveis, e sua identificação específica só pode ser feita com o estudo da estrutura da copínia.

Distribuição: o gênero foi registrado para o Brasil na região Sudeste, para os estados do Espírito Santo, Rio de Janeiro e São Paulo. ?Filellum serratum foi a única espécie deste gênero registrada para o Brasil, nas regiões Sudeste e Sul, para a área incluída entre os estados do Espírito Santo e Rio Grande do Sul (Migotto et al. 2002, 2004, Oliveira et al., no prelo). Entretanto, como as espécies do gênero Filellum podem ser diagnosticadas somente por meio da morfologia da copínia (Marques et al., 2011), consideramos o registro de ?Filellum serratum como duvidoso.

FAMÍLIA PLUMULARIIDAE McCrady, 1859a

Monotheca margaretta Nutting 1900. (Figura 15 a-c)

Monotheca margaretta Nutting 1900:72, pl. 11, Figuras 1-3; Migotto 1996:53-55, Figura 11a-c; Calder 1997:11-13, Figura 2a-d; Marques et al. 2006:85-86.

Monotheca margaretta f. typica Vannucci Mendes 1946:578, pl.5, Figura 48, pl. 6, Figura 54; Vannucci 1949:250; 1950:89.

Monotheca margaretta f. curta Vannucci Mendes 1946:578-579, pl.5, Figuras 49-50, pl. 6, Figura 55.

Monoteca margaretta f. typica Vannucci 1951:89 [grafia incorreta]. 
[Sinonímia mais completa em Calder 1997:11]

Material: Ponta das Garoupas, gonóforos ausentes, sobre Sargassum cymosum, 4 m, 16.X.1993, M.A. Haddad col. (MZUSP 4021); 4 m, 13.VIII.1994 (MZUSP 4022). Praia de Quatro Ilhas, gonóforos ausentes, sobre alga, 1-2 m, 28.XII.2002, A.C. Marques col. (MZUSP 4063). Praia da Tainha, gonóforos ausentes, sobre alga, 31.XII.2002, A.C. Marques col. (MZUSP 4064).

Descrição: colônias com altura 3-6 mm $(\mathrm{n}=10)$, surgindo diretamente da hidrorriza; hidrorriza com diâmetro 60-105 $\mu \mathrm{m}$ $(\mathrm{n}=10)$, nematotecas e septos internos; nematotecas da hidrorriza longas, com diâmetro reduzido proximalmente, comprimento 50$95 \mu \mathrm{m}(\mathrm{n}=10)$, diâmetro distal 25-40 $\mu \mathrm{m}(\mathrm{n}=10)$. Hidrocaule monossifônico, não ramificado, com crescimento simpodial, dividido em entrenós regulares por nós transversais. Entrenós, comprimento 228-258 $\mu \mathrm{m}(\mathrm{n}=10)$, diâmetro 29-43 $\mu \mathrm{m}(\mathrm{n}=10)$, com apófise distal, uma nematoteca mediana na direção oposta à apófise e duas a quatro nematotecas axilares. Hidrocládio dividido em dois entrenós, um atecado sem nematotecas, um tecado com três nematotecas: uma mediana inferior e duas laterais, todas com apófise. Entrenó tecado terminando entre apófises das nematotecas laterais, formando um Y na parede adcaulinar da região distal da hidroteca, comprimento 104-183 $\mu \mathrm{m}(\mathrm{n}=10)$, diâmetro 27-50 $\mu \mathrm{m}(\mathrm{n}=10)$. Entrenó atecado com comprimento 48-89 $\mu \mathrm{m}(\mathrm{n}=10)$, diâmetro 24-30 $\mu \mathrm{m}(\mathrm{n}=10)$. Hidroteca em forma de taça, parede adcaulinar convexa, parede abcaulinar côncava, borda lisa, sem septo intratecal; comprimento hidroteca

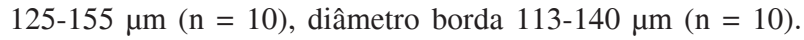
Nematotecas laterais em forma de cone, móveis, bicamerais, comprimento 5-75 $\mu \mathrm{m}(\mathrm{n}=20)$, diâmetro 25-40 $\mu \mathrm{m}(\mathrm{n}=20)$. Comprimento das nematotecas mesiais 55-75 $\mu \mathrm{m}(\mathrm{n}=10)$, diâmetro 30-45 $\mu \mathrm{m}(\mathrm{n}=10)$. Gonotecas não observadas.

Comentários: semelhante à descrição de Calder (1997) e Migotto (1996).

Distribuição: Monotheca margaretta foi registrada para o Brasil nas regiões Nordeste, Sudeste e Sul, para os estados do Ceará, Paraíba, Pernambuco, Alagoas, e a área incluída entre os estados da Bahia e Santa Catarina (Migotto et al. 2002,
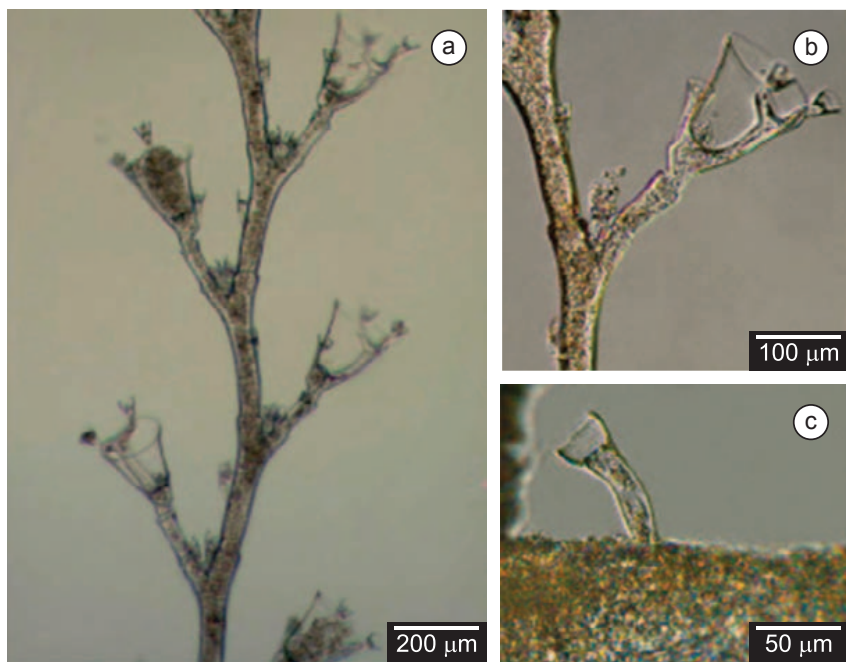

Figura 15. Monotheca margaretta Nutting 1900. a) Parte de uma colônia. b) Hidroteca. c) Nematoteca da hidrorriza.

Figure 15. Monotheca margaretta Nutting 1900. a) Part of a colony. b) Hydrotheca. c) Nematotheca of hydrorhiza.
Marques et al. 2006, Oliveira et al. 2006, Oliveira \& Marques 2007, Oliveira et al., no prelo).

\section{FAMÍLIA SERTULARIIDAE Lamouroux 1812}

Dynamena disticha (Bosc 1802). (Figura 16 a-c)

Sertularia disticha Bosc 1802:101, pl. 29, Figura 2.

Dynamena cornicina; Vannucci Mendes 1946:562-564, pl. 4, Figuras 33-34; Vannucci 1949:242-243; 1950:87; 1951: 84; Millard 1975:261-263, Figura 86a-e; Pires et al. 1992:6.

Dynamena disticha; Calder 1991:93-96, Figura 50a-c; Migotto 1996:62-64, Figura 12a-e.

[Sinonímia mais completa em Calder 1991:93]

Material: Ponta das Garoupas, gonóforos ausentes, sobre Sargassum cymosum, 4 m, 16.X.1993, M.A. Haddad col. (MZUSP 4023); gonóforos ausentes, 4 m, 11.I.1994 (MZUSP 4025); gonóforos presentes, 0-1,5 m, 28.V.1994 (MZUSP 4028); gonóforos ausentes, 1,5-3 m, 13.VIII.1994 (MZUSP 4030); gonóforos ausentes, 0-1,5 m, 13.VIII.1994 (MZUSP 4031). Praia da Sepultura, gonóforos presentes, sobre alga, 0-1 m, 29.XII.2002, A.C. Marques col. (MZUSP 4068). Praia de Bombas, gonóforos ausentes, sobre rocha, 0-1 m, 14.XI.2005, V. Shimabukuro col. (MZUSP 4081).
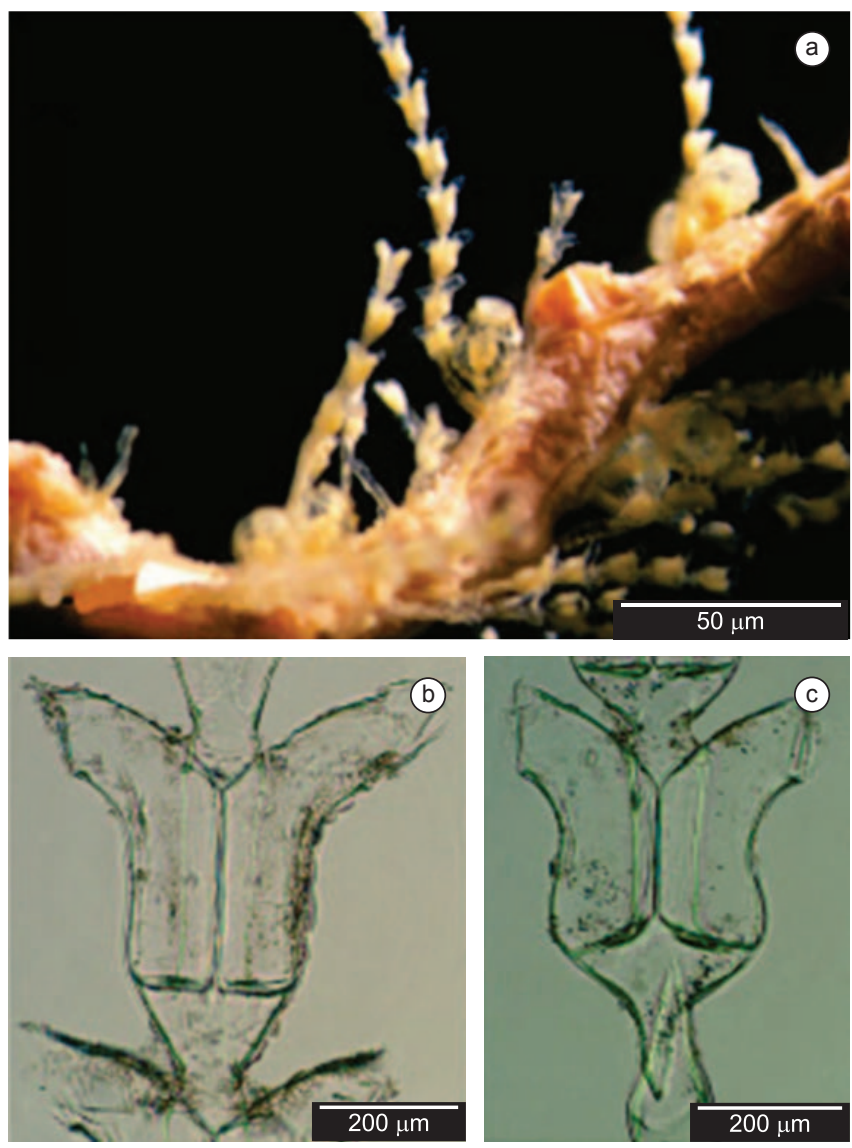

Figura 16. Dynamena disticha (Bosc 1802). a) Colônias com gonotecas. b) Par de hidrotecas medianas distais. c) Par de hidrotecas proximais.

Figure 16. Dynamena disticha (Bosc 1802). a) Colonies with gonothecae. b) Pair of distal median hydrothecae. c) Pair of proximal hydrothecae. 
Descrição: colônias eretas, altura 4-7 mm $(n=10)$, surgindo de hidrorriza com diâmetro 79-222 $\mu \mathrm{m}(\mathrm{n}=10)$. Hidrocaule monossifônico, não ramificado, dividido em entrenós por nós oblíquos. Parte atecada do hidrocaule com comprimento 350$1600 \mu \mathrm{m}(\mathrm{n}=10)$, separada da tecada por nó oblíquo com diâmetro $125-160 \mu \mathrm{m}(\mathrm{n}=10)$. Parte tecada do hidrocaule dividida em entrenós por nós oblíquos, cada entrenó com um par de hidrotecas opostas adnatas ao hidrocaule. Distância entre dois pares consecutivos de hidrotecas, desde a região apical de um dos pares até a base do outro par, 88-385 $\mu \mathrm{m}(\mathrm{n}=10)$. Hidrotecas cilíndricas, metade proximal paralela ao eixo do entrenó, metade distal curvada abcaulinarmente. Hidrotecas proximais mais largas, mais curtas e mais curvas que hidrotecas distais. Parede hidrotecal abcaulinar côncava, comprimento 247$397 \mu \mathrm{m}(\mathrm{n}=20)$. Parede adcaulinar hidrotecal com comprimento 233-379 $\mu \mathrm{m}(\mathrm{n}=20)$; parte livre da parede adcaulinar convexa, comprimento $147-235 \mu \mathrm{m}(\mathrm{n}=20)$; parte contínua da parede adcaulinar do par de hidrotecas reta, comprimento 172-277 $\mu \mathrm{m}$ $(n=10)$. Diâmetro basal hidrotecal 102-162 $\mu \mathrm{m}(\mathrm{n}=20)$. Margem hidrotecal com diâmetro 106-160 $\mu \mathrm{m}(\mathrm{n}=20)$, com duas cúspides agudas laterais e uma mediana adcaulinar. Perissarco espesso próximo à margem hidrotecal da parede adcaulinar, formando cúspide interna. Opérculo formado por uma valva abcaulinar maior, uma valva adcaulinar menor. Gonotecas ovais, até três por colônia, com pequeno pedículo e quatro a seis anelações transversais $(\mathrm{n}=10)$, surgindo direto da hidrorriza; comprimento das gonotecas 809-1250 $\mu \mathrm{m}(\mathrm{n}=10)$, maior diâmetro 539-873 $\mu \mathrm{m}$ ( $\mathrm{n}=10)$, diâmetro da abertura 285-396 $\mu \mathrm{m}(\mathrm{n}=10)$.

Comentários: Dynamena disticha (Bosc 1802) caracterizase pela presença de um par de hidrotecas por entrenó, além de hidrotecas proximais mais largas, mais curtas e mais curvas que as distais. Já sua congênere, D. quadridentata (Ellis \& Solander 1786), apresenta grupos contínuos de hidrotecas por entrenó e as bases das hidrotecas distais adjacentes às paredes adcaulinares das hidrotecas proximais, como observado por Calder (1991). Ambas as espécies possuem perissarco espessado na região marginal da hidroteca, fomando cúspide interna. Entretanto, D. quadridentata destaca-se por um espessamento mais intenso do perissarco, diferindo de $D$. disticha pela presença de cúspide interna tanto na parede abcaulinar quanto adcaulinar da hidroteca.

Uma das amostras da Ponta das Garoupas apresenta poucas colônias, com a maior parte delas danificadas e apenas dois a três pares de hidrotecas; as colônias com mais de três pares de hidrotecas possuem a maioria de suas hidrotecas quebradas. Material semelhante à descrição de Calder (1991) e Migotto (1996).

Distribuição: Dynamena disticha foi registrada para o Brasil nas regiões Nordeste, Sudeste e Sul, para os estados do Ceará, Pernambuco e a área incluída entre os estados da Bahia e Rio Grande do Sul (Migotto et al. 2002, Marques \& Migotto 2003, Oliveira et al. 2006, Oliveira \& Marques 2007, Amaral et al. 2009, Oliveira et al., no prelo).

Dynamena quadridentata (Ellis \& Solander 1786). (Figura 17 a-c)

Sertularia quadridentata Ellis \& Solander 1786:57-58, pl. 5, Figura g, G.

Dynamena quadridentata f. typica Vannucci Mendes 1946:559-561, pl. 3, Figuras 27, 28, 31; Vannucci 1949:241; 1950:87.

Dynamena quadridentata f. flabellata Vannucci Mendes 1946:561562, pl. 3, Figura 32; Vannucci 1949:242, t. 2, Figura 34.

Dynamena quadridentata f. heterodonta; Vannucci 1951:83-84, t.2, Figuras 11-12.

Dynamena quadridentata; Millard 1975:265-266, 268, Figura 87g-j; Calder 1991:96-98, Figura 51a-c; Migotto 1996:64-65, Figura 12f-g.
[Sinonímia mais completa em Calder 1991:96]

Material: Ponta das Garoupas, gonóforos ausentes, sobre Sargassum cymosum, 0-1,5 m, 13.VIII.1994, M.A. Haddad col. (MZUSP 4029); gonóforos ausentes, sobre Sargassum cymosum, 1,5-3 m (MZUSP 4033).

Descrição: colônias eretas, altura 2-3 mm $(\mathrm{n}=10)$, surgindo da hidrorriza com diâmetro 48-159 $\mu \mathrm{m}(\mathrm{n}=10)$; hidrocaule monossifônico, não ramificado, dividido em entrenós por nós oblíquos; parte atecada do hidrocaule com comprimento 206$603 \mu \mathrm{m}(\mathrm{n}=10)$, separada da tecada por um nó oblíquo com diâmetro 79-159 $\mu \mathrm{m}(\mathrm{n}=10)$; entrenós tecados com grupos contínuos de dois a cinco pares de hidrotecas opostas. Distância entre dois grupos contínuos e consecutivos de hidrotecas, desde a região apical de um dos grupos até a base do outro grupo, 143-365 $\mu \mathrm{m}(\mathrm{n}=10)$. Hidrotecas cilíndricas; parede abcaulinar côncava, comprimento 175-333 $\mu \mathrm{m}(\mathrm{n}=10)$; parede adcaulinar convexa nas hidrotecas proximais, reta nas hidrotecas distais, comprimento parte adnata $238-444 \mu \mathrm{m}(\mathrm{n}=10)$; parte contínua da parede adcaulinar do par de hidrotecas com comprimento 95-159 $\mu \mathrm{m}(\mathrm{n}=10)$; porção livre da parede adcaulinar com comprimento 48-127 $\mu \mathrm{m}(\mathrm{n}=10)$. Diâmetro basal da hidroteca $11-143 \mu \mathrm{m}(\mathrm{n}=10)$. Perissarco espessado próximo à abertura hidrotecal, formando duas cúspides internas: uma abcaulinar e outra adcaulinar. Abertura hidrotecal cilíndrica, margem com
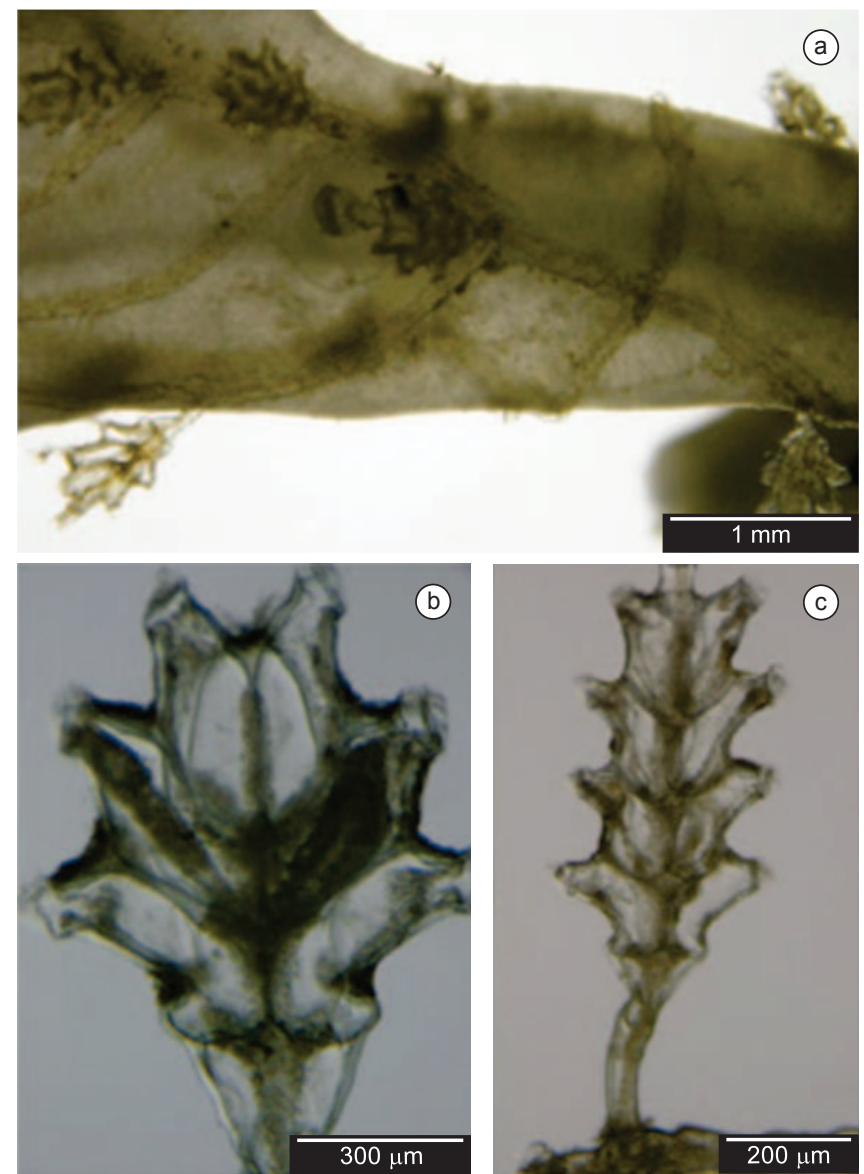

Figura 17. Dynamena quadridentata (Ellis \& Solander 1786). a) Colônia com diversos ramos sobre alga. b) Par de hidrotecas medianas com hidrantes. c) Conjunto de quatro pares de hidrotecas.

Figure 17. Dynamena quadridentata (Ellis \& Solander 1786). a) Colony with several branches on algae. b) Pair of median hydrothecae with hydranths. c) Four pairs of hydrothecae. 
duas cúspides laterais, uma cúspide adcaulinar pequena mediana. Diâmetro da abertura hidrotecal 63-95 $\mu \mathrm{m}(\mathrm{n}=10)$. Opérculo formado por uma valva abcaulinar maior, uma valva adcaulinar menor. Gonotecas não observadas.

Distribuição: Dynamena quadridentata foi registrada para o Brasil nas regiões Nordeste e Sudeste, para o estado de Alagoas e a área incluída entre os estados da Bahia e São Paulo (Migotto et al. 2002, Oliveira et al. 2006, Oliveira \& Marques 2007, Oliveira et al., no prelo). Este é o primeiro registro para a região Sul e para o estado de Santa Catarina.

Sertularella conica Allman 1877. (Figura 18 a-b)

Sertularella conica Allman 1877:21, pl. 15, Figuras 6, 7; Calder 1991:99-101, Figura 52a-d; Migotto 1996:67-68, Figura 12j-k.

Sertularella inconstans; Vannucci Mendes 1946:569, t.4, Figura, 38; Vannucci 1949:243-244, t. 2, Figuras 35-36; 1950:88.

[Sinonímia mais completa em Calder 1991:99]

Material: Ponta das Garoupas, gonóforos ausentes, sobre Sargassum cymosum, 1,5-3 m, 11.I.1994, M.A. Haddad col. (MZUSP 4027).

Descrição: colônia ereta, altura 2-5 mm $(\mathrm{n}=3)$, surgindo de hidrorriza com diâmetro 127-270 $\mu \mathrm{m}(\mathrm{n}=10)$; hidrocaule monossifônico, geniculado, não ramificado, dividido em entrenós por nós oblíquos; entrenós com uma hidroteca distal em forma de garrafa bojuda; eixo da hidroteca oblíquo em relação ao do hidrocaule, parede externa com duas a cinco $(n=10)$ anelações; parede abcaulinar com comprimento 413-540 $\mu \mathrm{m}(\mathrm{n}=10)$; hidroteca adnata ao entrenó até ca. da metade ou menos da metade do comprimento; parte adnata da parede adcaulinar com comprimento 190-270 $\mu \mathrm{m}(\mathrm{n}=10)$; parte livre com comprimento 286-365 $\mu \mathrm{m}(\mathrm{n}=10)$; diâmetro máximo da hidroteca 206-270 $\mu \mathrm{m}$ $(\mathrm{n}=10)$, diâmetro afilando distalmente. Margem hidrotecal com quatro cúspides, diâmetro 127-191 $\mu \mathrm{m}(\mathrm{n}=10)$; cúspides submarginais presentes. Opérculo piramidal, com quatro valvas. Gonotecas não observadas.

Comentários: material semelhante à descrição de Calder (1991).

Distribuição: Sertularella conica foi registrada para o Brasil nas regiões Sudeste e Sul, para a área incluída entre os estados do Espírito Santo e São Paulo, e estado do Rio Grande do Sul (Migotto et al. 2002, 2004, Grohmann 2006, Oliveira et al., no prelo). Este é o primeiro registro para o estado de Santa Catarina.
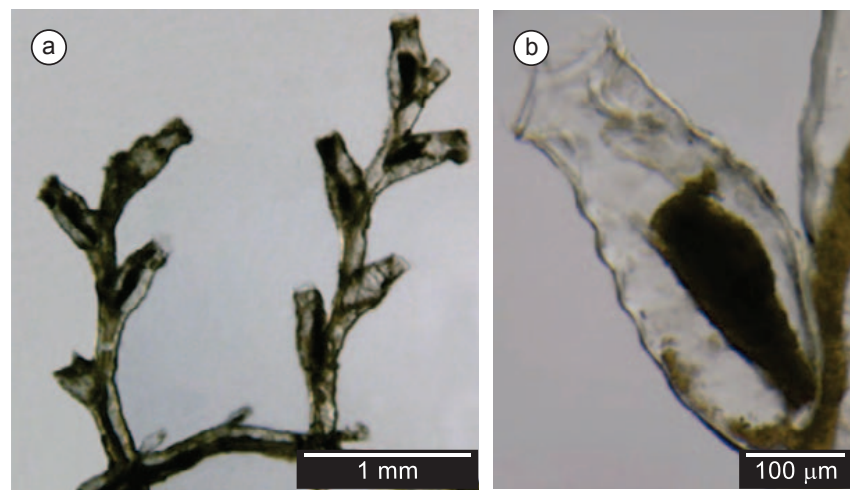

Figura 18. Sertularella conica Allman 1877. a) Aspecto geral da colônia. b) Hidroteca com hidrante.

Figure 18. Sertularella conica Allman 1877. a) General aspect of colony. b) Hydrotheca with hydranth.
Sertularia distans (Lamouroux 1816). (Figura 19 a-d)

Dynamena distans Lamouroux 1816:180, pl.5, Figura 1a-b.

Sertularia erasmoi Vannucci Mendes 1946:565-566, t. 2, Figura 18, t.3, Figuras 29-30; Vannucci 1949:245-246.

Sertularia minuscula Vannucci 1949:246-247, t. 2, Figura 42, t. 3, Figuras 43-44; 1950:88.

Sertularia distans; Millard 1975:306-307, Figura 99e-h; Mayal 1983:6-7; Pires et al. 1992:6-7; Migotto 1996:69-71, Figura 13b-e; Marques et al. 2006:88-89.

\section{Tridentata distans; Calder 1991:105-107, Figura 55a-c.}

[Sinonímia mais completa em Calder 1991:105]

Material: Ponta das Garoupas, gonóforos ausentes, sobre Sargassum cymosum, 1,5-3 m, 16.X.1993, M.A. Haddad col. (MZUSP 4024); gonóforos ausentes, 1,5-3 m, 11.I.1994 (MZUSP 4026).

Descrição: colônias eretas, altura 1,7-3 mm $(\mathrm{n}=10)$, surgindo da hidrorriza com septo, diâmetro 63-195 $\mu \mathrm{m}(\mathrm{n}=10)$; hidrocaule monossifônico, não ramificado, dividido em entrenós por nós transversais ou oblíquos. Parte atecada do hidrocaule com comprimento 158-413 $\mu \mathrm{m}(\mathrm{n}=10)$, separada da tecada por um nó oblíquo de diâmetro 63-127 $\mu \mathrm{m}(\mathrm{n}=10)$; entrenós longos, com um par de hidrotecas opostas. Hidrotecas distais mais eretas que as proximais. Distância entre dois pares consecutivos de hidrotecas, desde a região apical de um dos pares até a base do outro par,
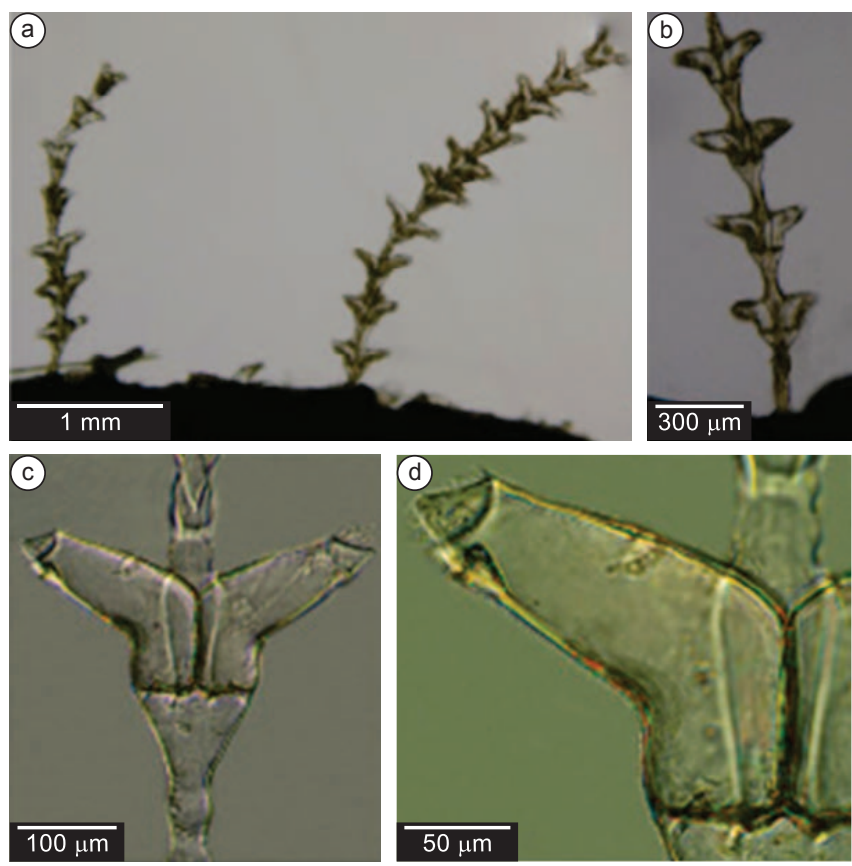

Figura 19. Sertularia distans (Lamouroux 1816). a) Aspecto geral da colônia. b) Detalhe da porção proximal da colônia. c) Par de hidrotecas medianas. d) Detalhe da hidroteca com cúspide interna e projeções basais do perissarco em direção ao entrenó.

Figure 19. Sertularia distans (Lamouroux 1816). a) General aspect of the colony. b) Detail of the proximal portion of the colony. c) Pair of median hydrothecae. d) Detail of hydrotheca with internal cusp and proximal projections of perissarc towards internode. 
63-127 $\mu \mathrm{m}(\mathrm{n}=10)$; parede abcaulinar da hidroteca côncava, comprimento 127-238 $\mu \mathrm{m}(\mathrm{n}=10)$, com uma cúspide interna na margem; parte livre da parede adcaulinar reta, comprimento 111-190 $\mu \mathrm{m}(\mathrm{n}=10)$; porção adnata da parede adcaulinar com comprimento $111-175 \mu \mathrm{m}(\mathrm{n}=10)$; parte contínua da parede adcaulinar do par de hidrotecas com comprimento 63-211 $\mu \mathrm{m}$ $(n=10)$; base da hidroteca com projeções do perissarco em direção ao entrenó, diâmetro 48-79 $\mu \mathrm{m}(\mathrm{n}=10)$; margem hidrotecal com duas cúspides laterais, uma mediana adcaulinar, diâmetro 48-63 $\mu \mathrm{m}$ $(\mathrm{n}=10)$; opérculo composto por duas valvas, uma abcaulinar maior, uma adcaulinar menor. Gonotecas não observadas.

Comentários: Sertularia distans (Lamouroux 1816) difere de suas congêneres, S. marginata (Kirchenpauer 1864) e S. turbinata (Lamouroux 1816), principalmente pela morfologia das hidrotecas, as quais se caracterizam pela presença de cúspide interna, projeções do perissarco em direção ao entrenó e ausência de septo intratecal. O formato das hidrotecas de S. distans e $S$. turbinata é semelhante e ambas possuem as hidrotecas distais mais eretas que as proximais. Entretanto, as hidrotecas de $S$. distans são mais longas e afiladas e formam um ângulo reto com o eixo do hidrocaule. Já S. marginata apresenta hidrotecas infladas e curvadas frontalmente, sendo suas colônias facilmente reconhecidas pela forma pinada e hidrocládios alternos. Material semelhante à descrição de Calder (1991) e Migotto (1996).

Distribuição: Sertularia distans foi registrada para o Brasil nas regiões Nordeste, Sudeste e Sul, para os estados do Ceará, Paraíba, Pernambuco, Alagoas e a área incluída entre os estados da Bahia e Santa Catarina (Migotto et al. 2002, Marques \& Migotto 2003, Marques et al. 2006, Oliveira et al. 2006, Oliveira \& Marques 2007, Amaral et al. 2009, Oliveira et al., no prelo).

Sertularia marginata (Kirchenpauer 1864). (Figura 20 a-d)

Dynamena marginata Kirchenpauer 1864:13, Figura 8a-c.

Sertularia marginata; Vannucci Mendes 1946:567-568, pl. 3, Figura 31a, pl. 4, Figuras. 36-37; Millard 1975:311-312, Figura 99a-d; Pires et al. 1992:7; Migotto 1996:73-75, Figura 14a-c; Marques et al. 2006:90.

Sertularia marginata f. typica Vannucci 1949:248; 1951:84; 1954:115.

Sertularia marginata f. laxa Vannucci 1949:248-249, pl. 3, Figura 46; 1950:88; 1951:84.

Tridentata marginata; Calder 1991:107-109, Figuras 56-57a-b.

[Sinonímia mais completa em Calder 1991:107]

Material: Praia de Quatro Ilhas, gonóforos ausentes, sobre alga, 1-2 m, 28.XII.2002, A.C. Marques col. (MZUSP 4065). Praia da Sepultura, gonóforos presentes, sobre rocha, 0-1 m, 29.XII.2002, A.C. Marques col. (MZUSP 4070). Praia da Tainha, gonóforos ausentes, sobre rocha, 31.XII.2002, A.C. Marques col. (MZUSP 4071). Praia de Bombas, gonóforos ausentes, sobre Sargassum sp., rocha e alga não identificada, 0-1 m, 14.XI.2005, V. Shimabukuro col. (MZUSP 4082); gonóforos ausentes, sobre Sargassum sp.e alga não identificada, 0-1 m, 13.XI.2005 (MZUSP 4083).

Descrição: colônias eretas, pinadas, altura até $25 \mathrm{~mm}(\mathrm{n}=10)$, surgindo diretamente da hidrorriza, diâmetro 142-243 $\mu \mathrm{m}$ $(\mathrm{n}=10)$. Hidrocaule monossifônico, dividido em entrenós por nós transversais, com hidrocládios alternados. Parte atecada do hidrocaule relativamente curta, comprimento $1142-5730 \mu \mathrm{m}$ ( $\mathrm{n}=10)$, separada do restante por nó oblíquo, diâmetro 253$412 \mu \mathrm{m}(\mathrm{n}=10)$. Entrenó do hidrocaule com três hidrotecas adnatas (uma axilar na apófise, duas sub-opostas distais no entrenó), uma apófise proximal que sustenta hidrocládio, separada desse por nó oblíquo. Hidrocládios alternados, comprimento 1571-5238 $\mu \mathrm{m}(\mathrm{n}=10)$, divididos em entrenós por nós oblíquos, cada entrenó composto por um par de hidrotecas opostas. Hidroteca inflada, curvada distal e abcaulinarmente, adnata ao entrenó do hidrocládio até cerca da metade do comprimento da parede adcaulinar; comprimento da parede abcaulinar 103-473 $\mu \mathrm{m}(\mathrm{n}=10)$, comprimento da parte adnata da parede adcaulinar 159-494 $\mu \mathrm{m}(\mathrm{n}=10)$, comprimento da parte livre da parede adcaulinar 27-308 $\mu \mathrm{m}(\mathrm{n}=10)$. Septo intratecal e espessamento perissarcal próximos à margem; margem com três cúspides sendo duas laterais, uma cúspide menor adcaulinar. Diâmetro da borda da hidroteca 78-125 $\mu \mathrm{m}(\mathrm{n}=10)$, diâmetro da base da hidroteca 66-164 $\mu \mathrm{m}(\mathrm{n}=10)$. Opérculo com uma valva abcaulinar maior, uma adcaulinar menor dividida ao meio. Hidrante com ceco abcaulinar. Gonoteca surgindo do hidrocaule, cilíndrica, com até sete anelações transversais; comprimento 1269-1428 $\mu \mathrm{m}(\mathrm{n}=10)$, diâmetro máximo 682-730 $\mu \mathrm{m}(\mathrm{n}=10)$.

Distribuição: Sertularia marginata foi registrada para o Brasil nas regiões Nordeste, Sudeste e Sul, para os estados do Ceará, Paraíba, Pernambuco, Alagoas e para a área incluída entre os estados da Bahia e Santa Catarina (Migotto et al. 2002, Marques \& Migotto 2003, Marques et al. 2006, Oliveira et al. 2006, Oliveira \& Marques 2007, Amaral et al. 2009, Oliveira et al., no prelo).

Sertularia turbinata (Lamouroux 1816). (Figura 21 a-d)
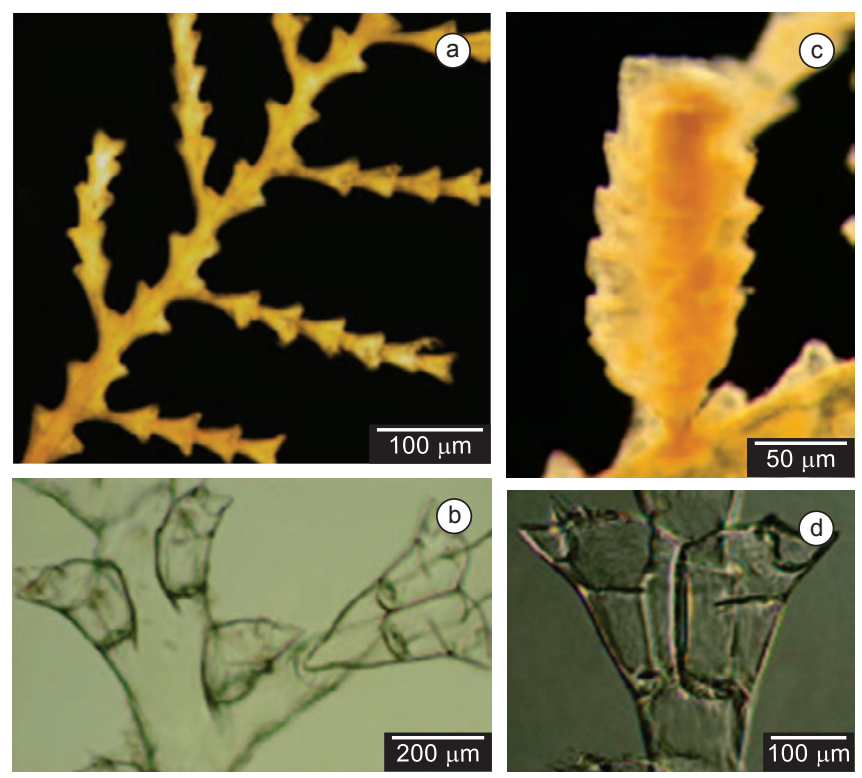

Figura 20. Sertularia marginata (Kirchenpauer 1864). a) Porção mediana de uma colônia. b) Hidrocaule com hidrotecas e porção proximal de um hidrocládio. c) Gonoteca com gonóforos. d) Detalhe de um par de hidrotecas.

Figure 20. Sertularia marginata (Kirchenpauer 1864). a) Median portion of a colony. b) Hydrocaulus with hydrothecae and proximal portion of hydrocladium. c) Gonotheca with gonophores. d) Details of a pair of hydrothecae. 
Dynamena turbinata Lamouroux 1816:180.

Sertularia turbinata; Vannucci 1949:244-245, pl. 2, Figuras 38-41; Millard 1975:312-313, Figura 100b-c, e; Maÿal 1983:5-6; Migotto 1996:78-79, Figura 14f-g.

Geminella ceramensis; Vannucci Mendes 1946:570-571, pl. 4, Figuras 40-41.

Sertularia drachi Vannucci 1949:247-248, pl. 3, Figura 45.

Tridentata turbinata; Calder 1991:110-112, Figura 60.

[Sinonímia mais completa em Calder 1991:110-111]

Material: Ponta das Garoupas, gonóforos ausentes, sobre Sargassum cymosum, 1,5-3 m, 13.VIII.1994, M.A. Haddad col. (MZUSP 4032); gonóforos ausentes, 0-1,5 m, 13.VIII.1994 (MZUSP 4034); gonóforos ausentes, 0-1,5 m, 28.V.1994 (MZUSP 4035). Praia de Quatro Ilhas, gonóforos ausentes, sobre alga, 1-2 m, 28.XII.2002, A.C. Marques col. (MZUSP 4066). Praia do Canto Grande, gonóforos ausentes, em trapiche sobre rocha, 30.XII.2002, A.C. Marques col. (MZUSP 4067). Praia da Sepultura, gonóforos ausentes, sobre rocha e alga, 0-1 m, 29.XII.2002, A.C. Marques col. (MZUSP 4069). Praia de Bombas, gonóforos ausentes, sobre Sargassum sp. e alga não identificada, 0-1 m, 13.XI.2005, V. Shimabukuro col. (MZUSP 4084); sobre Sargassum sp., Sertularia marginata e rocha, 0-1 m, 14.XI.2005 (MZUSP 4085).

Descrição: colônias eretas com altura até $10 \mathrm{~mm}(\mathrm{n}=10)$, surgindo diretamente da hidrorriza, diâmetro 100-240 $\mu \mathrm{m}$ $(n=10)$. Hidrocaule monossifônico, não ramificado, parte atecada curta, comprimento 270-13200 $\mu \mathrm{m}(\mathrm{n}=10)$, separada da parte tecada por nó oblíquo, diâmetro 120-200 $\mu \mathrm{m}(\mathrm{n}=10)$. Parte tecada dividida em entrenós por nós oblíquos, cada entrenó composto por um par de hidrotecas opostas. Hidrotecas adnatas ao hidrocaule, parede adcaulinar parcialmente contígua, exceto nos pares proximais que não se tocam; comprimento da parte adnata da parede adcaulinar 190-332 $\mu \mathrm{m}(\mathrm{n}=10)$, comprimento da parte
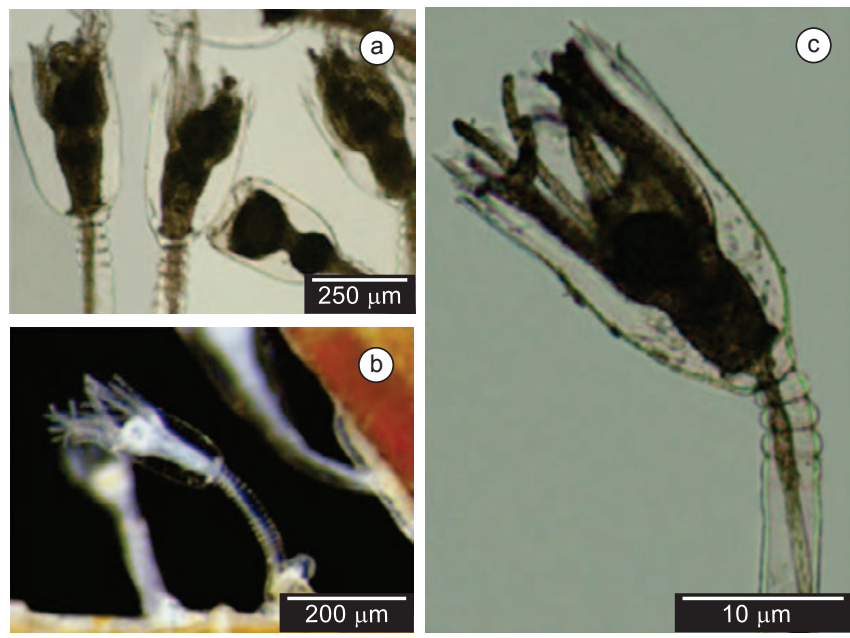

Figura 21. Sertularia turbinata (Lamouroux 1816). a) Aspecto geral de uma colônia epifítica. b) Detalhe de dois pares de hidrotecas com hidrantes distendidos. c, d) Hidrotecas com hidrantes distendidos e retraídos.

Figure 21. Sertularia turbinata (Lamouroux 1816). a) General aspect of an epiphytic colony. b) Detail of two pairs of hydrothecae with distended hydranths. c, d) Hydrothecae with distended and retracted hydranths. livre da parede adcaulinar 140-259 $\mu \mathrm{m}(\mathrm{n}=10)$, comprimento da parede abcaulinar 184-356 $\mu \mathrm{m}(\mathrm{n}=10)$. Septo intratecal e perissarco das paredes abcaulinar e adcaulinar espessados próximo à margem. Hidrotecas alargadas na região proximal em relação ao septo intratecal, estreitando distalmente, curvando-se distal e abcaulinarmente. Pares de hidrotecas distais mais eretos e longos que proximais. Margem hidrotecal com duas cúspides agudas laterais, uma cúspide pequena adcaulinar; diâmetro da borda da hidroteca $65-160 \mu \mathrm{m}(\mathrm{n}=10)$, diâmetro da base da hidroteca 77-165 $\mu \mathrm{m}(\mathrm{n}=10)$. Hidrantes longos, com hipostômios na forma de domo e um verticilo de ca. 15-22 tentáculos $(\mathrm{n}=10)$. Gonotecas não observadas.

Comentários: exemplares de Canto Grande e Sepultura com hidrantes contraídos e/ou danificados. Material semelhante à descrição de Migotto (1996).

Distribuição: Sertularia turbinata foi registrada para o Brasil nas regiões Nordeste, Sudeste e Sul, para os estados do Ceará, Alagoas e para a área incluída entre os estados do Espírito Santo e Santa Catarina (Migotto et al. 2002, Oliveira et al. 2006, Oliveira \& Marques 2007, Amaral et al. 2009, Oliveira et al., no prelo).

Ordem Proboscoida Broch 1910

\section{FAMÍLIA CAMPANULARIIDAE Johnston 1836}

Clytia gracilis (M. Sars 1851). (Figura 22 a-c)

Laomedea gracilis M. Sars 1851:138.

Clytia attenuata; Vannucci Mendes 1946:548-549, pl. 1, Figuras 8-9; Vannucci 1949:233-234, pl. 2, Figuras 19-20.

Clytia elsea-oswaldae; Vannucci Mendes 1946:550-551, pl. 2, Figuras 12-13, 19.

Clytia cylindrica; Vannucci 1949:232-233, pl. 1, Figura 14; 1950:8485, pl. 1, Figura 2; Vannucci \& Ribeiro 1955:70-73, Figuras 1-9 [medusa].

\section{Clytia hemisphaerica; Millard 1975:217-218, Figura 72a-d.}

Clytia gracilis; Migotto 1996:81-82, Figura 15c; Calder 1991:5457, Figura 31a-d; Cornelius 1995b:246-251, Figura 56a-h; Hirohito 1995:63-64, Figura 18c-g; Marques et al. 2006:81.

[Sinonímia mais completa em Calder 1991:54-55]

Material: Ponta das Garoupas, gonóforos ausentes, sobre Sargassum cymosum, 4 m, 16.X.1993, M.A. Haddad col. (MZUSP 4017). Praia de Quatro Ilhas, gonóforos ausentes, sobre Eudendrium carneum, 1-2 m, 28.XII.2002, A.C. Marques col. (MZUSP 4052). Praia da Sepultura, gonóforos ausentes, sobre alga, 0-1 m, 29.XII.2002, A.C. Marques col. (MZUSP 4055). Praia da Tainha, gonóforos ausentes, sobre alga, briozoário, Eudendrium carneum, Macrorhynchia philippina e Sertularia marginata, 31.XII.2002, A.C. Marques col. (MZUSP 4056); gonóforos ausentes, sobre briozoário, 31.XII.2002 (MZUSP 4058).

Descrição: colônias geralmente estoloniais, poucas eretas, surgindo diretamente de hidrorriza. Quando eretas, hidrocaule monossifônico, ramificado irregularmente. Pedículos anelados proximal e distalmente, comprimento 249-2676 $\mu \mathrm{m}(\mathrm{n}=10)$, diâmetro 47-154 $\mu \mathrm{m}(\mathrm{n}=10)$, podendo haver anelações ou ondulações medianas, ou pedículos totalmente anelados. Hidroteca campanuliforme ou cônica, com diafragma transversal, margem com até 15 cúspides agudas, separadas por incisões em 


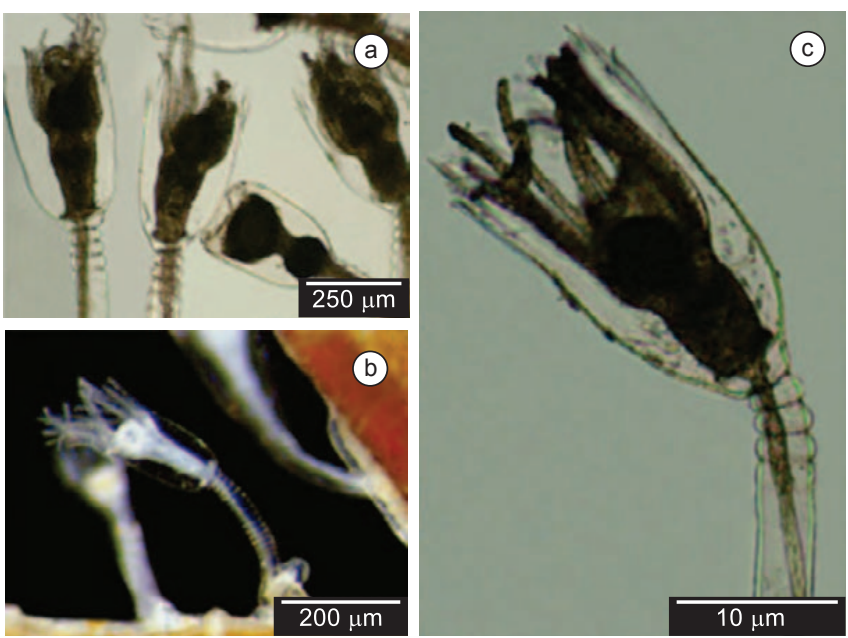

Figura 22. Clytia cf. gracilis (M. Sars 1851). a, b) Hidrotecas. c) Aspecto geral de um pólipo epizóico de Eudendrium carneum.

Figure 22. Clytia cf. gracilis (M. Sars 1851). a, b) Hydrothecae. c) General aspect of an epizoic polyp of Eudendrium carneum Clarke 1882.

forma de 'U', geralmente inclinadas no sentido anti-horário; comprimento da hidroteca 237-784 $\mu \mathrm{m}(\mathrm{n}=10)$, diâmetro da borda da hidroteca 164-495 $\mu \mathrm{m}(\mathrm{n}=10)$, diâmetro da base da hidroteca 61-291 $\mu \mathrm{m}(\mathrm{n}=10)$. Gonotecas não observadas.

Comentários: colônias epizoicas de diversos animais, tais como Eudendrium carneum, Macrorhynchia philippina, Sertularia marginata e briozoários; outras epifíticas, sendo algumas sobre Sargassum cymosum. Material semelhante à descrição de Calder (1991) e Migotto (1996).

Distribuição: o pólipo de Clytia gracilis foi registrado para o Brasil nas regiões Nordeste, Sudeste e Sul, para os estados do Ceará, Pernambuco, e para a área incluída entre os estados de Alagoas e Paraná (Migotto et al. 2002, 2004, Kelmo \& Attrill 2003, Marques \& Migotto 2003, Marques et al. 2006, Oliveira et al. 2006, Oliveira \& Marques 2007, Amaral et al. 2009, Oliveira et al., no prelo). Este é o primeiro registro para o estado de Santa Catarina.

Obelia dichotoma (Linnaeus 1758). (Figura 23 a-d)

Sertularia dichotoma Linnaeus 1758:812.

Obelia braziliensis; Vannucci Mendes 1946:553, pl. 2, Figuras 20-21; Vannucci 1949:231 [grafia incorreta].

Obelia commissuralis; Vannucci 1951:80, pl. 2, Figuras 8-9; 1954:110.

Obelia griffini; Vannucci Mendes 1946:552, pl. 2, fig, 16-17; Vannucci 1954:110.

Obelia hyalina; Vannucci 1949:230, pl. 1, Figuras 12-13.

Obelia dichotoma; Cornelius 1975:265-272, Figuras 3a-b, 4a-f; Millard 1975:227-229, Figura 75f-j; Calder 1991:72-76, Figura 38ad; Cornelius 1995b:296-300, Figura 69a-k; Migotto 1996:88-90, Figura 16d; Marques et al. 2006:81-82.

[Sinonímia mais completa em Cornelius 1975:265-267 e Calder 1991:72-73]
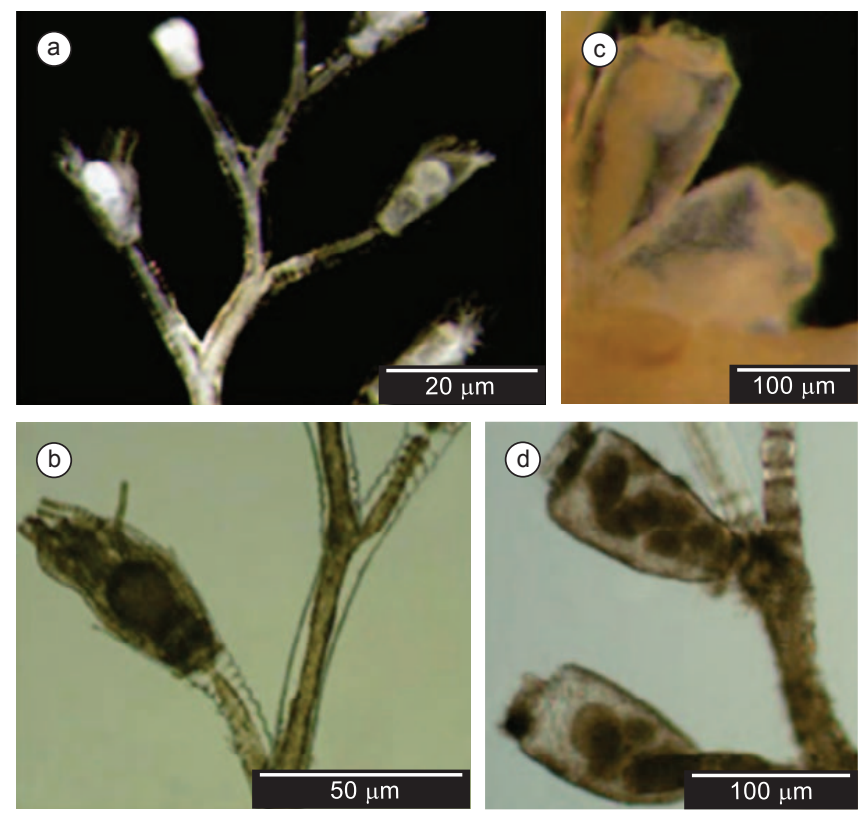

Figura 23. Obelia dichotoma (Linnaeus 1758). a) Aspecto geral de um colônia. b) Hidroteca com hidrante retraído. c, d) Gonotecas com gonóforos. Figure 23. Obelia dichotoma (Linnaeus 1758). a) General aspect of a colony. b) Hydrotheca with retracted hydranth. c, d) Gonothecae with gonophores.

Material: Ponta das Garoupas, gonóforos ausentes, sobre Sargassum cymosum, 4 m, 12.VIII.1994, M.A. Haddad col. (MZUSP 4016). Praia de Quatro Ilhas, gonóforos ausentes, sobre rocha, Eudendrium carneum, 1-2 m, 28.XII.2002, A.C. Marques col. (MZUSP 4051). Praia da Tainha, gonóforos presentes, sobre rocha, alga, Eudendrium carneum, porífero e briozoário, 31.XII.2002, A.C. Marques col. (MZUSP 4057). Praia de Bombas, gonóforos ausentes, sobre Sargassum sp. e alga não identificada, 0-1 m, 13.XI.2005, V. Shimabukuro col. (MZUSP 4074); gonóforos ausentes, sobre Sargassum sp., 0-1 m, 14.XI.2005 (MZUSP 4075).

Descrição: colônias eretas, simpodiais, surgindo de hidrorriza. Hidrocaule monossifônico, não ramificado ou ramificado, comprimento 150-725 $\mu \mathrm{m}(\mathrm{n}=10)$, diâmetro 75-150 $\mu \mathrm{m}(\mathrm{n}=10)$, dividido em entrenós regulares, anelados basalmente, com um pedículo distal. Pedículo com anelações nas regiões proximal e distal, ou todo anelado, comprimento 154-797 $\mu \mathrm{m}(\mathrm{n}=10)$, diâmetro 58-97 $\mu \mathrm{m}(\mathrm{n}=10)$. Hidroteca campanuliforme, com diafragma oblíquo, margem hidrotecal lisa; comprimento da hidroteca 178-327 $\mu \mathrm{m}(\mathrm{n}=10)$, diâmetro da borda da hidroteca 165-373 $\mu \mathrm{m}(\mathrm{n}=10)$, diâmetro da base da hidroteca 70-130 $\mu \mathrm{m}$ $(\mathrm{n}=10)$. Hidrante com hipostômio esférico (material fixado), 12-25 tentáculos filiformes $(\mathrm{n}=10)$. Gonoteca lisa, cilíndrica ou, geralmente, cônica, truncada distalmente, com uma abertura distal em um pequeno pescoço tubular; comprimento 518-1106 $\mu \mathrm{m}$ ( $\mathrm{n}=10)$, diâmetro máximo 209-338 $\mu \mathrm{m}(\mathrm{n}=10)$. Pedículos da gonoteca curtos, totalmente anelados, surgindo da região axilar do pedículo da hidroteca.

Comentários: Obelia dichotoma (Linnaeus 1758) é caracterizada principalmente pela presença de diafragma oblíquo, embora esta característica seja compartilhada com Obelia longissima (Pallas, 1766), que não ocorre no Brasil. Pode ser facilmente distinguida de Obelia geniculata (Linnaeus 1758), a qual possui diafragma 
transversal, perissarco levemente espessado, hidrotecas mais arredondadas e pedículos mais curvos.

As colônias de $O$. dichotoma são epifíticas, algumas sobre Sargassum cymosum ou epizoicas de diversos animais, tais como Eudendrium carneum, briozoários, cracas e esponja. Material semelhante à descrição de Calder (1991) e Migotto (1996).

Distribuição: o pólipo de Obelia dichotoma foi registrado para o Brasil nas regiões Nordeste, Sudeste e Sul, para o estado do Ceará, para a área incluída entre os estados de Sergipe e Rio Grande do Sul (Migotto et al. 2002, Kelmo \& Attrill 2003, Marques \& Migotto 2003, Marques et al. 2006, Oliveira et al. 2006, Oliveira \& Marques 2007, Oliveira et al., no prelo).

Obelia geniculata (Linnaeus 1758). (Figura 24 a-d)

Sertularia geniculata Linnaeus 1758:812.

Obelia geniculata; Vannucci Mendes 1946:551-552, t. 2, Figuras 1415; Vannucci 1949:232; 1950:84; Cornelius 1975:272-278, Figuras 1a-d, 5a-c; Cornelius 1995b:301-303, Figura 70a-g; Migotto 1996:90-91, Figura 16e.

[Sinonímia mais completa em Cornelius 1975:272-273]

Material: Ponta das Garoupas, gonóforos ausentes, sobre Sargassum cymosum, 4 m, 16.X.1993, M.A. Haddad col. (MZUSP 4008); gonóforos ausentes, 1,5-3 m, 13.VIII.1994 (MZUSP 4015). Praia de Bombas, gonóforos ausentes, sobre Sargassum sp., 0-1 m, 14.XI.2005, V. Shimabukuro col. (MZUSP 4076).

Descrição: colônias eretas, altura 3-7 mm $(\mathrm{n}=10)$, surgindo de hidrorriza com diâmetro 48-175 $\mu \mathrm{m}(\mathrm{n}=10)$; hidrocaule monossifônico e simpodial. Perissarco levemente espessado. Entrenós com anelações basais e apófise distal dando origem a pedículo hidrotecal; comprimento do entrenó 397-666 $\mu \mathrm{m}$ ( $\mathrm{n}=10)$, diâmetro 95-159 $\mu \mathrm{m}(\mathrm{n}=10)$; pedículo da hidroteca com duas a sete $(n=10)$ anelações, comprimento 111-397 $\mu \mathrm{m}$
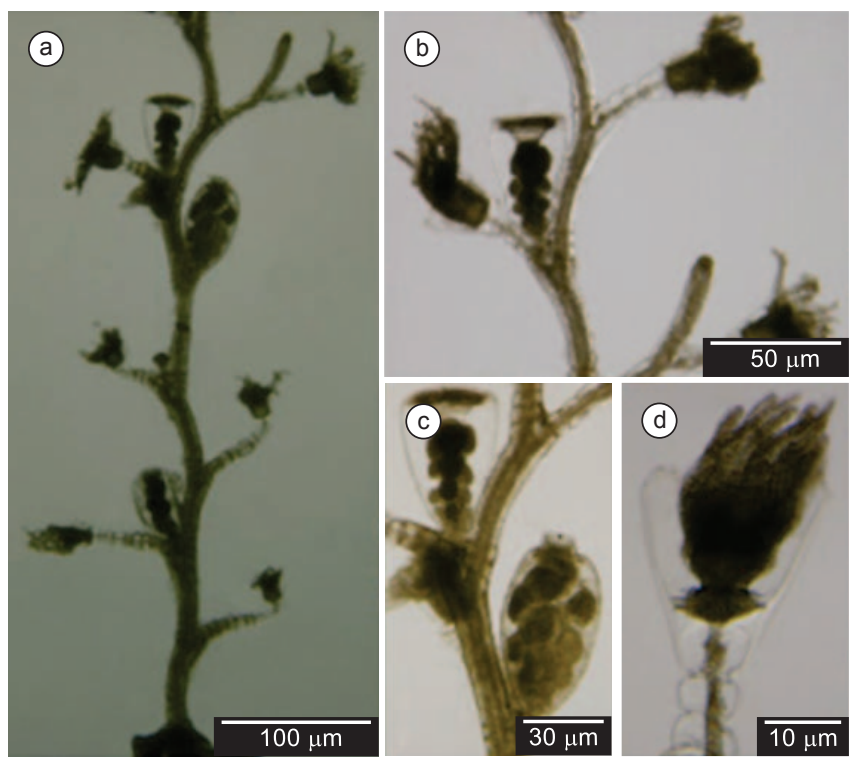

Figura 24. Obelia geniculata (Linnaeus 1758). a) Porções proximal e mediana de uma colônia fértil. b) Detalhe de um ramo com pólipos e gonângio. c) Gonângios. d) Hidroteca.

Figure 24. Obelia geniculata (Linnaeus 1758). a) Proximal and median portions of a fertile colony. b) Detail of a branch with polyps and gonangium. c) Gonangia. d) Hydrotheca.
( $\mathrm{n}=10)$, diâmetro 79-111 $\mu \mathrm{m}(\mathrm{n}=10)$; hidroteca campanuliforme com comprimento 143-397 $\mu \mathrm{m}(\mathrm{n}=10)$, diâmetro na borda 190$317 \mu \mathrm{m}(\mathrm{n}=10)$; diâmetro no nível do diafragma 95-286 $\mu \mathrm{m}$ $(\mathrm{n}=10)$; margem da hidroteca lisa, diafragma transversal. Gonotecas lisas, pediceladas, cônico-invertidas a cilíndricas, algumas truncadas distalmente, comprimento 365-730 $\mu \mathrm{m}$ ( $\mathrm{n}=10)$, diâmetro máximo 70-317 $\mu \mathrm{m}(\mathrm{n}=10)$, diâmetro na borda $159-413 \mu \mathrm{m}(\mathrm{n}=10)$. Pedículo da gonoteca curto, totalmente anelado, surgindo da região axilar do pedículo hidrotecal.

Distribuição: o pólipo de Obelia geniculata foi registrado para o Brasil, nas regiões Nordeste, Sudeste e Sul, para o estado de Alagoas e para a área incluída entre os estados do Espírito Santo e Rio Grande do Sul (Migotto et al. 2002, Oliveira et al. 2006, Oliveira \& Marques 2007, Oliveira et al., no prelo).

Orthopyxis integra (MacGillivray 1842). (Figura 25 a-d)

Campanularia integra MacGillivray 1842:465.

?Orthopyxis clytioides; Vannucci Mendes 1946:546-547, est. 1, Figuras 6-7.

?Orthopyxis minuta Vannucci 1949:234-235, t. 1, Figuras 15-17, t.2, Figura 18.

Orthopyxis integra; Cornelius 1982:60-67, Figura 6a-h; 1995b:235239, Figura 54a-n.

Material: Ponta das Garoupas, gonóforos ausentes, sobre Sargassum cymosum, 0-1,5 m, 16.X.1993, M.A. Haddad col. (MZUSP 4007). Praia de Quatro Ilhas, gonóforos ausentes, sobre alga, 1-2 m, 28.XII.1992, A.C. Marques col. (MZUSP 4053). Praia de Bombas, gonóforos ausentes, sobre alga, 0-1 m, 13.XI.2005, V. Shimabukuro col. (MZUSP 4078).
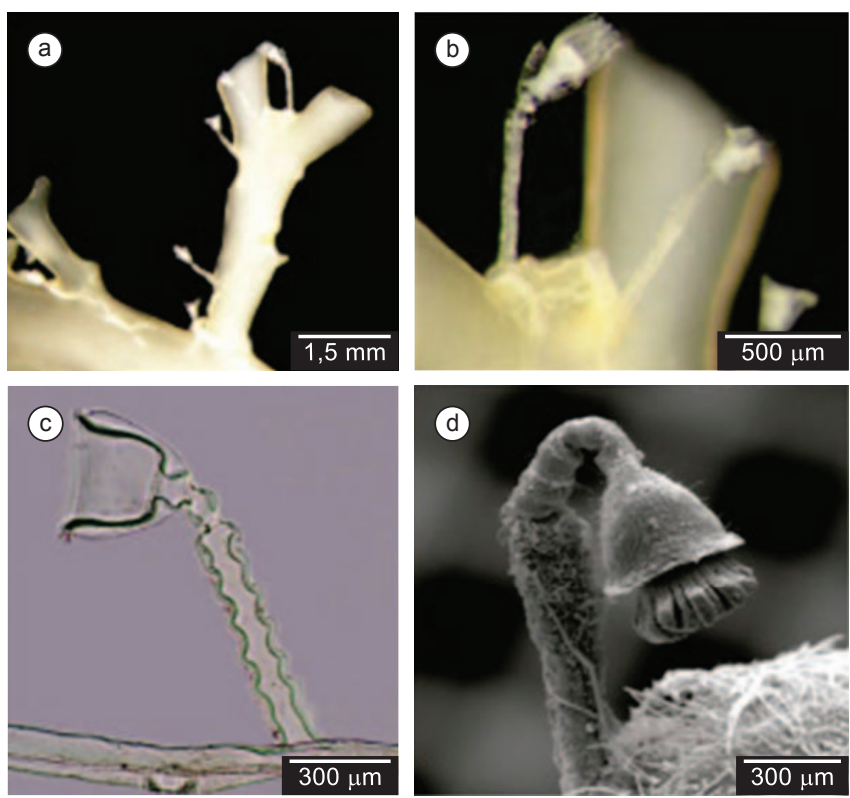

Figura 25. Orthopyxis integra (Macgillivray 1842). a) Colônia epifítica. b) Detalhe do pólipo com hidrante distendido. c) Aspecto geral do perissarco. d) Microscopia eletrônica de varredura do hidrocaule e hidroteca com hidrante.

Figure 25. Orthopyxis integra (Macgillivray 1842). a) Epiphytic colony. b) Detail of polyp with distended hydranth. c) General aspect of perisarc. d) Scanning electron microscopy of hydrocaulus and hydrotheca with hydranth. 
Descrição: colônias estoloniais, altura 682-1349 $\mu \mathrm{m}(\mathrm{n}=10)$, surgindo de hidrorriza tortuosa com diâmetro 79-143 $\mu \mathrm{m}(\mathrm{n}=10)$. Perissarco do hidrocaule e hidroteca de espessura variável. Pedículos ondulados ou totalmente anelados, com até $10(\mathrm{n}=10)$ anelações; altura do pedículo 397-952 $\mu \mathrm{m}(\mathrm{n}=10)$, diâmetro 63-111 $\mu \mathrm{m}(\mathrm{n}=10)$. Esférula sub-hidrotecal presente. Hidrotecas campanuliformes, sem diafragma, altura 206-429 $\mu \mathrm{m}(\mathrm{n}=10)$, diâmetro na borda 190-333 $\mu \mathrm{m}(\mathrm{n}=10)$, diâmetro no nível do diafragma 111-238 $\mu \mathrm{m}(\mathrm{n}=10)$. Margem lisa. Gonotecas não observadas.

Comentários: Orthopyxis integra (MacGillivray 1842) diferencia-se de $O$. sargassicola (Nutting 1915) principalmente pela ausência de cúspides na borda da hidroteca e gonotecas alongadas, cilíndricas e lisas (ver Cornelius 1982, 1995b). Já O. sargassicola apresenta borda da hidroteca com cúspides que variam de arredondadas a afiladas e gonotecas curtas totalmente aneladas (ver Migotto 1996). Em ambas as espécies os indivíduos de uma mesma colônia possuem grande variação na espessura do perissarco e na morfologia do pedículo, o qual pode possuir ondulações, ser totalmente anelado ou apresentar anelações e ondulações. Essas espécies assemelham-se à descrição de O. crenata (Hartlaub 1901) de Millard (1975), Cornelius (1982) e Watson (2005), principalmente em relação à espessura variável do perissarco e morfologia do pedículo. Entretanto, diferentemente de suas congêneres, O. crenata (Hartlaub 1901) caracteriza-se pela presença de "[...] hydrothecal rims smooth through gently wavy to crenate." (Cornelius 1982:59). Essa última característica é intermediária entre $O$. integra e $O$. sargassicola e pode levar a identificações errôneas, devido à semelhança entre essas espécies, associada à sua ampla variação morfológica.

As colônias são epifíticas, algumas sobre Sargassum cymosum. Material semelhante à descrição de Cornelius (1995b).

Distribuição: Orthopyxis integra foi registrada para o Brasil nas regiões Sudeste e sul, para a área incluída entre os estados do Espírito Santo e Santa Catarina (Vannucci Mendes 1946, Vannucci,1949, 1951, Oliveira \& Marques 2007, Oliveira et al., no prelo).

Orthopyxis sargassicola (Nutting 1915). (Figura 26 a-d)

Clytia sargassicola Nutting 1915:57-58, pl. 12, Figuras 8-9.

Orthopyxis lennoxensis; Vannucci Mendes 1946:544-546, est. 1, Figuras 3-5; Vannucci 1951:81.

Orthopyxis minuta Vannucci 1949:234-235, est. 1, Figuras 15-17, est. 2, Figura 18.

Orthopyxis crenata; Vannucci 1954:111-112.

Orthopyxis billardi Vannucci 1954:112-114, pl. 3, Figuras 4-7, pl. 4, Figura 6.

Orthopyxis sargassicola; Calder 1991:51-53, Figura 30a-d; Migotto 1996:91-92, Figura 16f-i.

Material: Ponta das Garoupas, gonóforos ausentes, sobre Sargassum cymosum, 4 m, 16.X.1993, M.A. Haddad col. (MZUSP 4005); gonóforos ausentes, 1,5-3 m, 16.X.1993 (MZUSP 4006); gonóforos ausentes, 1,5-3 m, 11.I.1994 (MZUSP 4009); gonóforos ausentes, 4 m, 11.I.1994 (MZUSP 4010); gonóforos ausentes, 0-1,5 m, 28.V.1994 (MZUSP 4011); gonóforos ausentes, 4 m, 13.VIII.1994 (MZUSP 4012); gonóforos ausentes, 1,5-3 m, 13.VIII.1994 (MZUSP 4013); gonóforos ausentes, 0-1,5 m, 13.VIII.1994 (MZUSP 4014).
Praia de Bombas, gonóforos ausentes, sobre Sargassum sp. e alga não identificada, 0-1 m, 14.XI.2005, V. Shimabukuro col. (MZUSP 4077); gonóforos ausentes, sobre Sargassum sp., 0-1 m, 14.XI.2005 (MZUSP 4079).

Descrição: colônias estoloniais, altura 1000-2063 $\mu \mathrm{m}(\mathrm{n}=10)$, surgindo de hidrorriza tortuosa com diâmetro 48-206 $\mu \mathrm{m}(\mathrm{n}=10)$. Perissarco do hidrocaule e hidroteca de espessura variável. Pedículos ondulados ou totalmente anelados, com até $18(\mathrm{n}=10)$ anelações; altura do pedículo 603-1508 $\mu \mathrm{m}(\mathrm{n}=10)$, diâmetro 63-1269 $\mu \mathrm{m}(\mathrm{n}=10)$. Esférula sub-hidrotecal presente. Hidrotecas campanuliformes, algumas mais alongadas e cilíndricas, sem diafragma, altura 349-476 $\mu \mathrm{m}(\mathrm{n}=10)$, diâmetro na borda 190$445 \mu \mathrm{m}(\mathrm{n}=10)$, diâmetro no nível do diafragma 95-238 $\mu \mathrm{m}$ $(n=10)$. Margem da hidroteca com oito a 10 cúspides levemente arredondadas, separadas por incisões em 'U'; algumas hidrotecas com margem aparentemente lisa. Perissarco da região da borda praticamente não espessado. Gonotecas não observadas.

Comentários: colônias sem gonóforo, epifíticas, sendo que algumas estão sobre Sargassum cymosum e Sargassum sp. Alguns indivíduos parecem não apresentar cúspides, assemelhando-se com $O$. integra. Entretanto, alguns desses indivíduos sofreram um dobramento da margem da hidroteca, o que resulta em uma aparente ausência de cúspides.

O material é semelhante à descrição de $O$. sargassicola de Calder (1991) e Migotto (1996).

Distribuição: Orthopyxis sargassicola foi registrada para o Brasil, nas regiões Nordeste, Sudeste e Sul, para o estado de Alagoas e para a área incluída entre os estados do Espírito Santo e Santa Catarina (Migotto et al. 2002, Oliveira et al. 2006, Oliveira \& Marques 2007, Oliveira et al., no prelo).
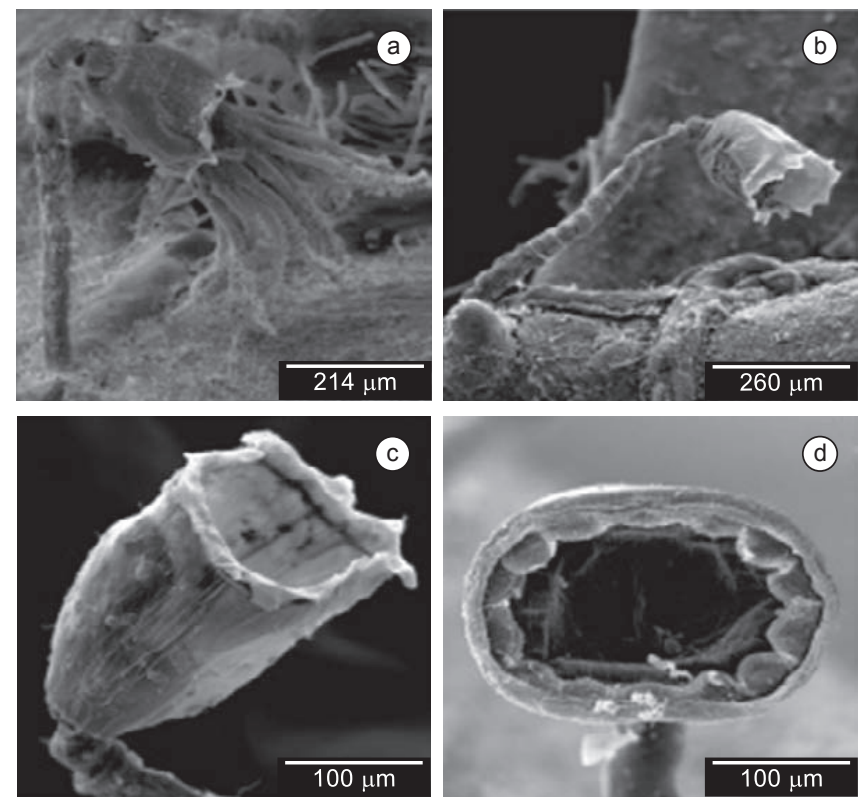

Figura 26. Microscopia eletrônica de varredura de Orthopyxis sargassicola (Nutting 1915). a) Pólipo com hidrante distendido. b) Aspecto geral do perissarco. c) Borda da hidroteca com cúspides. d) Vista oral de hidroteca com borda dobrada.

Figure 26. Scanning electron microscopy of Orthopyxis sargassicola (Nutting 1915). a) Polyp with distended hydranth. b) General aspect of perisarc. c) Margin of hydrotheca with cusps. d) Oral view of a hydrotheca with margin bended in. 


\section{Discussão}

Dentre as 25 espécies encontradas em Bombinhas, 10 possuem registros mais austrais no litoral uruguaio e argentino: Bimeria vestita, Bougainvillia muscus, Clytia gracilis, Dynamena disticha, Halecium tenellum, Hebella scandens, Obelia dichotoma, Obelia geniculata, Orthopyxis integra e Sertularella conica (Tabela 1). Em relação ao litoral do Brasil, as espécies cosmopolitas D. disticha, $O$. dichotoma, O. geniculata e $S$. conica possuem seu registro mais austral no estado do Rio Grande do Sul. Outras espécies cosmopolitas, tais como Aglaophenia latecarinata, Eudendrium carneum, Macrorhynchia philippina, Monotheca margaretta, Sertularia distans e $S$. marginata, apresentam seu registro mais austral no estado de Santa Catarina. Já B. vestita e $C$. gracilis, espécies também consideradas cosmopolitas, apresentavam seus registros mais austrais no litoral dos estados de São Paulo e Paraná, respectivamente, sendo que, a partir deste estudo, seus registros foram estendidos até Santa Catarina (Tabela 1).

Todas as espécies encontradas apresentam uma descontinuidade quanto à sua distribuição geográfica no litoral brasileiro (Tabela 1). Entretanto, espécies que aparentemente possuem uma distribuição geográfica ampla e/ou contínua no litoral do Brasil (e.g., C. gracilis, D. disticha, M. philippina, M. margaretta, O. dichotoma, O. geniculata, S. distans, S. marginata; Tabela 1) foram registradas na literatura de forma pontual e esparsa (Oliveira et al., no prelo) para o restante da costa sul-americana. Esta descontinuidade na distribuição das espécies de hidroides bentônicos pode estar relacionada com a escassez de amostragens na costa sul-americana e à existência de poucos estudos sobre biodiversidade marinha na região, considerando-se particularmente os hidroides bentônicos.

Dentre as 25 espécies encontradas neste estudo, apenas cinco são primeiros registros para Santa Catarina (B. vestita, C. floccosa,
C. gracilis, D. quadridentata, $S$. conica), enquanto que $B$. vestita, $C$. floccosa e D. quadridentata são primeiros registros para a região Sul do Brasil (Tabela 1). Isto representa um acréscimo de $12 \%$ e 5,5\% nos registros de espécies de hidroides para Santa Catarina e litoral sul-brasileiro, respectivamente.

As espécies foram encontradas sobre diferentes substratos que variaram de acordo com o local de coleta. Na Ponta das Garoupas, por exemplo, todos os animais coletados eram epifíticos e foram encontrados sobre Sargassum cymosum. Já os animais coletados na praia da Tainha foram encontrados sobre rochas e algas, mas também como epizoicos de outros hidroides, cracas, esponjas e briozoários.

Marques et al. (2003) demonstraram que o número de registros de espécies de hidroides no litoral do Brasil vem aumentando ao longo do tempo e sugeriram que essa seria uma tendência conforme estudos taxonômicos se intensificassem. $\mathrm{O}$ aumento do número de registros de espécies de hidroides bentônicos aqui encontrados corrobora essa tendência e indica que a biodiversidade de hidroides do litoral catarinense ainda é subestimada, confirmando a necessidade da intensificação de estudos taxonômicos nessa área.

\section{Agradecimentos}

Nós agradecemos aos técnicos do Depto. de Zoologia (Instituto de Biociências, Universidade de São Paulo), Eduardo Mattos (in memoriam) e Enio Mattos, pela ajuda na microscopia eletrônica de varredura e confecção das eletromicrografias. Um revisor anônimo e Alberto Lindner colaboraram com comentários e sugestões. O estudo recebeu financiamento do CNPq (PIBIC, 305735/2006-3, 490348/2006-8, 304720/2009-7, 562143/2010-6, 563106/2010-7), FAPESP (Proc. 2004/09961-4, 2006/58226-0, 2010/06927-0) e CAPES Procad, Prodoc e Pró-equipamentos.

Tabela 1. Lista das espécies de hidroides bentônicos (exceto hidrocorais) encontradas até 2010 para o litoral de Santa Catarina.

Table 1. Checklist of benthic hydroid species (hydrocorals not included) recorded until 2010 for the coast of Santa Catarina State.

\begin{tabular}{|c|c|c|c|}
\hline Espécies & Estado & $\begin{array}{c}\text { Primeiro } \\
\text { registro } \\
\text { para Santa } \\
\text { Catarina }\end{array}$ & $\begin{array}{c}\text { Registros } \\
\text { para o litoral } \\
\text { do Uruguai e } \\
\text { Argentina }\end{array}$ \\
\hline Acharadria crocea (L. Agassiz, 1862) & ES, RJ, SP, PR, SC, RS & - & $\mathrm{X}$ \\
\hline Acryptolaria sp.1 & $\mathrm{PR}, \mathrm{SC}$ & - & - \\
\hline Acryptolaria sp. 2 & $\mathrm{SP}, \mathrm{PR}, \mathrm{SC}$ & - & - \\
\hline Aglaophenia latecarinata Allman 1877 & MA, PI, CE, RN, PB, PE, BA, ES, RJ, SP, PR, SC & - & - \\
\hline Bimeria vestita Wright 1859 & $\mathrm{CE}, \mathrm{AL}, \mathrm{SE}, \mathrm{BA}, \mathrm{ES}, \mathrm{RJ}, \mathrm{SP}$ & $\mathrm{X}$ & $\mathrm{X}$ \\
\hline Bougainvillia muscus (Allman 1863) & $\mathrm{AL}, \mathrm{PR}, \mathrm{SC}$ & - & $\mathrm{X}$ \\
\hline Bougainvillia sp. & $\mathrm{SP}, \mathrm{PR}, \mathrm{SC}$ & - & - \\
\hline Cladocoryne floccosa Rotch 1871 & PE, AL, SE, BA, ES, RJ, SP & $\mathrm{X}$ & - \\
\hline Clytia gracilis (M. Sars 1851) & CE, PE, AL, SE, BA, ES, RJ, SP, PR & $\mathrm{X}$ & $\mathrm{X}$ \\
\hline Clytia hummelincki (Leloup, 1935) & PE, SE, BA, PR, SC & - & - \\
\hline
\end{tabular}

$\mathrm{O}$ símbolo $(\mathrm{X})$ refere-se às espécies com primeiro registro para Santa Catarina e com registro para o litoral do Uruguai e Argentina (Oliveira et al., no prelo). Os códigos usados para os estados, do norte ao sul do país, são: PA: Pará; MA: Maranhão; PI: Piauí; CE: Ceará; RN: Rio Grande do Norte; PB: Paraíba; PE: Pernambuco; AL: Alagoas; SE: Sergipe; BA: Bahia; ES: Espírito Santo; RJ: Rio de Janeiro; SP: São Paulo; PR: Paraná; SC: Santa Catarina; RS: Rio Grande do Sul.

The symbol (X) refers to the species first recorded for Santa Catarina and for the coast of Uruguay and Argentina (O.M.P. Oliveira et al., unpublished data). Codes used for the states, from north to south of the country, are: PA: Pará; MA: Maranhão; PI: Piauí; CE: Ceará; RN: Rio Grande do Norte; PB: Paraíba; PE: Pernambuco; AL: Alagoas; SE: Sergipe; BA: Bahia; ES: Espírito Santo; RJ: Rio de Janeiro; SP: São Paulo; PR: Paraná; SC: Santa Catarina; RS: Rio Grande do Sul. 
Tabela 1. Continuação...

Table 1. Continued...

\begin{tabular}{|c|c|c|c|}
\hline Espécies & Estado & $\begin{array}{c}\text { Primeiro } \\
\text { registro } \\
\text { para Santa } \\
\text { Catarina }\end{array}$ & $\begin{array}{c}\text { Registros } \\
\text { para o litoral } \\
\text { do Uruguai e } \\
\text { Argentina }\end{array}$ \\
\hline Clytia noliformis (McCrady, 1859a) & AL, BA, ES, RJ, SP, SC & - & $\mathrm{X}$ \\
\hline Clytia sp. & AL, RJ, SP, SC & - & - \\
\hline Corymorpha januarii Steenstrup, 1854 & RJ, SP, PR, SC, RS & - & $\mathrm{X}$ \\
\hline Coryne pusilla Gaertner, 1774 & ES, RJ, SP, PR, SC & - & - \\
\hline Coryne sp. & CE, SP, SC & - & - \\
\hline Dynamena crisioides Lamouroux, 1824 & CE, PB, PE, AL, SE, BA, ES, RJ, SP, PR, SC & - & - \\
\hline Dynamena disticha (Bosc 1802) & CE, PE, BA, ES, RJ, SP, PR, SC, RS & - & $\mathrm{X}$ \\
\hline Dynamena quadridentata (Ellis \& Solander 1786) & $\mathrm{AL}, \mathrm{BA}, \mathrm{ES}, \mathrm{RJ}, \mathrm{SP}$ & $\mathrm{X}$ & - \\
\hline Eudendrium carneum Clarke, 1882 & CE, RN, PB, PE, AL, SE, BA, ES, RJ, SP, PR, SC & - & - \\
\hline ?Eudendrium merulum Watson, 1985 & $\mathrm{SC}$ & - & - \\
\hline ?Filellum serratum (Clarke, 1879) & ES, RJ, SP, PR, SC, RS & - & $\mathrm{X}$ \\
\hline Halecium dyssymetrum Billard 1929 & ES, SP, SC & - & - \\
\hline Halecium sp. & SP, SC & - & - \\
\hline Halecium tenellum Hincks 1861 & $\mathrm{PE}, \mathrm{SP}, \mathrm{SC}$ & - & $\mathrm{X}$ \\
\hline Hebella scandens (Bale 1888) & CE, ES, RJ, SP, PR, SC & - & $\mathrm{X}$ \\
\hline Lafoea sp. & RJ, PR, SC & - & - \\
\hline Lafoeina amirantensis (Millard \& Bouillon, 1973) & PE, ES, RJ, SP, SC & - & - \\
\hline Macrorhynchia philippina Kirchenpauer 1872 & PE, AL, BA, ES, RJ, SP, SC & - & - \\
\hline Monotheca margaretta Nutting 1900 & CE, PB, PE, AL, BA, ES, RJ, SP, PR, SC & - & - \\
\hline Obelia bidentata Clark, 1875 & PE, SE, BA, RJ, SP, SC & - & $\mathrm{X}$ \\
\hline Obelia dichotoma (Linnaeus 1758) & CE, SE, BA, ES, RJ, SP, PR, SC, RS & - & $\mathrm{X}$ \\
\hline Obelia geniculata (Linnaeus 1758) & AL, ES, SP, PR, SC, RS & - & $\mathrm{X}$ \\
\hline Orthopyxis integra (MacGillivray 1842) & ES, SP, PR, SC & - & $\mathrm{X}$ \\
\hline Orthopyxis sargassicola (Nutting 1915) & $\mathrm{AL}, \mathrm{ES}, \mathrm{RJ}, \mathrm{SP}, \mathrm{PR}, \mathrm{SC}$ & - & - \\
\hline Orthopyxis sp. & $\mathrm{SC}$ & - & - \\
\hline Pennaria disticha Goldfuss, 1820 & CE, PB, PE, AL, SE, BA, ES, RJ, SP, PR, SC & - & - \\
\hline Pycnotheca mirabilis (Allman 1883) & $\mathrm{PB}, \mathrm{ES}, \mathrm{RJ}, \mathrm{SP}, \mathrm{SC}$ & - & - \\
\hline Sertularella conica Allman 1877 & ES, RJ, SP, RS & $\mathrm{X}$ & $\mathrm{X}$ \\
\hline Sertularella sp. & $\mathrm{PA}, \mathrm{BA}, \mathrm{RJ}, \mathrm{PR}, \mathrm{SC}$ & - & - \\
\hline Sertularia distans (Lamouroux 1816) & CE, PB, PE, AL, BA, ES, RJ, SP, PR, SC & - & - \\
\hline Sertularia marginata (Kirchenpauer 1864) & CE, PB, PE, AL, BA, ES, RJ, SP, PR, SC & - & - \\
\hline Sertularia turbinata (Lamouroux 1816) & $\mathrm{CE}, \mathrm{AL}, \mathrm{ES}, \mathrm{RJ}, \mathrm{SP}, \mathrm{PR}, \mathrm{SC}$ & - & - \\
\hline Sphaerocoryne sp. & $\mathrm{BA}, \mathrm{SC}$ & - & - \\
\hline Turritopsis nutricula McCrady, 1859b & PE, SE, BA, ES, RJ, SP, PR, SC, RS & - & - \\
\hline Ventromma halecioides (Alder, 1859) & PE, ES, RJ, SP, SC & - & - \\
\hline Zygophylax ?geniculata (Clarke, 1894) & $\mathrm{PR}, \mathrm{SC}$ & - & - \\
\hline Zyzzyzus warreni Calder 1988 & PE, AL, SP, SC & - & - \\
\hline
\end{tabular}

$\mathrm{O}$ símbolo $(\mathrm{X})$ refere-se às espécies com primeiro registro para Santa Catarina e com registro para o litoral do Uruguai e Argentina (Oliveira et al., no prelo). Os códigos usados para os estados, do norte ao sul do país, são: PA: Pará; MA: Maranhão; PI: Piauí; CE: Ceará; RN: Rio Grande do Norte; PB: Paraíba; PE: Pernambuco; AL: Alagoas; SE: Sergipe; BA: Bahia; ES: Espírito Santo; RJ: Rio de Janeiro; SP: São Paulo; PR: Paraná; SC: Santa Catarina; RS: Rio Grande do Sul.

The symbol (X) refers to the species first recorded for Santa Catarina and for the coast of Uruguay and Argentina (O.M.P. Oliveira et al., unpublished data). Codes used for the states, from north to south of the country, are: PA: Pará; MA: Maranhão; PI: Piauí; CE: Ceará; RN: Rio Grande do Norte; PB: Paraíba; PE: Pernambuco; AL: Alagoas; SE: Sergipe; BA: Bahia; ES: Espírito Santo; RJ: Rio de Janeiro; SP: São Paulo; PR: Paraná; SC: Santa Catarina; RS: Rio Grande do Sul. 


\section{Referências Bibliográficas}

AGASSIZ, A. 1865. North American Acalephae. Illustrated Catalogue of the Museum of Comparative Zoology. Harvard College, Cambridge.

AGASSIZ, L. 1862. Contributions to the natural history of the United States of America. Little, Brown \& Co., Boston, v.4.

ALDER, J. 1859. Descriptions of three new species of sertularian zoophytes. Ann. mag. nat. hist 3(3):353-356.

ALLMAN, G.J. 1863. Notes on the Hydroida. I. On the structure of Corymorpha nutans. II. Diagnoses of new species of Tubularidae obtained, during the autumn of 1862 , on the coasts of Shetland and Devonshire. Ann. mag. nat. hist. 11(3):1-12.

ALLMAN, G.J. 1872. A monograph of the gymnoblastic or tubularian hydroids. Conclusion of part I, and part II, containing descriptions of the genera and species of the Gymnoblastea. Ray Society, London.

ALLMAN, G.J. 1877. Report on the Hydroida collected during the exploration of the Gulf Stream by L.F. De Pourtalès, assistant United States Coast Survey. Mem. Mus. Comp. Zool. Harvard. 5(2):1-66.

ALLMAN, G.J. 1883. Report on the Hydroida dredged by H.M.S. Challenger during the years 1873-76. Part I. Plumularidae. In Report of the scientific results of the voyage of H.M.S. Challenger (J. Murray, ed.). Neill and Co. Zoology, Edinburgh, v.7, p.1-55.

AMARAL, F.M.D., RAMOS, C.A.C., LEÃO, Z.M.A.N., KIKUCHI, R.K.P., LIMA, K.K.M., LONGO, L.L., CORDEIRO, R.T.S., LIRA, S.M.A. \& VASCONCELOS, S.L. 2009. Checklist and morphometry of benthic cnidarians from the Fernando de Noronha Archipelago, Brazil. Cah. Biol. Mar. 50:277-290.

BALE, W.M. 1888. On some new and rare Hydroida in the Australian Museum Collection. P. Linn. Soc. N. S. W. 3:745-799.

BENEDEN van, P.J. 1844. Recherches sur l'embryogénie des tubulaires, et l'histoire naturelle des différents genres de cette famille qui habitent la Côte d'Ostende. Nouv. Mém. Acad. R. Sci. Bruxelles 17(6):1-72.

BILLARD, A. 1929. Note sur un genre nouveau et quelques espèces nouvelles d'Halecidae. Bull. Soc. Zool. Fr. 54:305-307.

BOSC, L.A.G. 1802. Histoire naturelle des vers, contenant leur description et leur moeurs; avec figures dessinées d'après nature. Guilleminet, Paris, v.2.

BROCH, H. 1910. Die hydroiden der arktischen meere. Fauna Arct. 5:129-247.

CALDER, D.R. 1988. Shallow-water hydroids of Bermuda: the Athecatae. Life Sci. Contr. R. Ontario Mus. 148:1-107.

CALDER, D.R. 1991. Shallow-water hydroids of Bermuda: the Thecatae, exclusive of Plumularioidea. Life Sci. Contr. R. Ontario Mus. 154:1-140.

CALDER, D.R. 1997. Shallow-water hydroids of Bermuda: supefamily Plumularioidea. Life Sci. Contr. R. Ontario Mus. 161:1-85.

CAMPOS, C.J., MARQUES, A.C. \& MIGOTTO, A.E. 2007. A taxonomic revision of the genus Zyzzyzus Stechow, 1921 (Cnidaria: Hydrozoa: Tubulariidae). Zootaxa 1627:1-22.

CLARK, S.F. 1875. Descriptions of new and rare species of hydroids from the New England Ocean. Trans. Conn. Acad. Arts Sci. 3:58-66.

CLARKE, S.F. 1879. Report on the Hydroida collected during the exploration of the Gulf Stream and Gulf of Mexico by Alexander Agassiz, 1877-78. Bull. Mus. Comp. Zool. Harvard Coll. 5(10):239-257.

CLARKE, S.F. 1882. New and interesting hydroids from Chesapeake Bay. Mem. Boston Soc. Nat. His. 3:135-145.

CLARKE, S.F. 1894. Reports on the dredging operations off the west Ocean of Central America to the Galapagos, to the West Ocean of Mexico, and in the Gulf of California, in charge of Alexander Agassiz, carried on by the U.S. Fish Commission Steamer "Albatross", during 1891, Lieut. Commander Z.L. Tanner, U.S.N. Commanding. The Hydroids. Bull. Mus. Comp. Zool. Harvard Coll. 25(6):71-77.

CORNELIUS, P.F.S. 1975. The hydroids species of Obelia (Coelenterata, Hydrozoa: Campanulariidae), with notes on the medusa stage. Bull. Br. Mus. Nat. Hist. 28(6):250-293.
CORNELIUS, P.F.S. 1982. Hydroids and medusae of the family Campanulariidae recorded from the eastern North Atlantic, with a world synopsis of genera. Bull. Br. Mus. Nat. Hist. 42(2):37-148.

CORNELIUS, P.F.S. 1992. Medusa loss in leptolid Hydrozoa (Cnidaria), hydroid rafting, and abbreviated life-cycles among their remote-island faunae: an interim review. Sci. Mar., 56:245-261.

CORNELIUS, P.F.S. 1995a. North-west European Thecate hydroids and their medusae. The Linnean Society of London and the Estuarine and Coastal Sciences Association, Shrewsbury, v. 50, Part 1.

CORNELIUS, P.F.S. 1995b. North-west European Thecate hydroids and their medusae. The Linnean Society of London and the Estuarine and Coastal Sciences Association, Shrewsbury, v. 50, Part 2.

ELLIS, J. \& SOLANDER, D. 1786. The natural history of many curious and uncommon zoophytes, collected from various parts of the globe. White, London.

FLEMING, J. 1828. A history of British animals, exhibiting the descriptive characters and systematical arrangement of the genera and species of quadrupeds, birds, reptiles, fishes, Mollusca and Radiata of the United Kingdom. Bell and Bradfute, Edinburgh.

FRASER, C.M. 1912. Some hydroids of Beaufort North Carolina. Bull. US Bur. Fish. 30(762):339-387.

GOLDFUSS, G.A. 1820. Handbuch der Zoologie. Johann Leonhard Schrag, Nürenberg.

GOY, J. 1979. Campagne de la Calypso au large des côtes atlantiques de l’Amérique du Sud (1961-1962). Méduses. Resul. scient. camp. Calypso 11:263-296.

GROHMANN, P.A., NOGUEIRA, C. \& DA SILVA, V.M.A. 2003. Hydroids (Cnidaria, Hydrozoa) collected on the continental Ocean of Brazil during the Geomar X Oceanographic Operation. Zootaxa 299:1-19.

GROHMANN, P.A. 2006. Importância dos acompanhamentos de longa duração no estudo da biodiversidade: exemplo da fauna de hidróides (Cnidaria) da Baía do Espírito Santo. Floresta e ambient. 13:97-112.

HARTLAUB, C. 1901. Hydroiden aus dern Stillen Ocean. Ergebnisse einer Reise nach dem Pacific (Schauinsland 1896-97). Zool. Jahrb. 14(6):349379.

HARTLAUB, C. 1904. Hydroiden. Expédition Antartique Belge. Résult. voyage S.Y. Belgica 7:1-19.

HINCKS, T. 1861. A catalogue of the zoophytes of South Devon and South Cornwall. Ann. mag. nat. hist. 8:251-262.

HINCKS, T. 1868. A history of the British hydroid zoophytes. John Van Voorst Paternoster Row, London, v.1.

HIROHITO, EMPEROR SHOWA. 1988. The hydroids of Sagami Bay. Biological Laboratory Imperial Household, Tokyo.

HIROHITO, EMPEROR SHOWA. 1995. The hydroids of Sagami Bay IIThecata. Biological Laboratory Imperial Household, Tokyo.

JOHNSTON, G. 1836. A catalogue of the zoophytes of Berwickshire. Berw. Naturalist's Club Proc. 1:107-108.

KELMO, F. \& DE SANTA-ISABEL, L.M. 1998. The athecatae hydroids (Cnidaria, Hydrozoa) from Northern Bahia, Brazil. Rev. Biol. Trop. 46(supl. 5):61-72.

KELMO, F. \& ATTRILL, M.J. 2003. Shallow-water Campanulariidae (Hydrozoa, Leptothecatae) from northern Bahía, Brazil. Rev. biol. trop. 51:123-146.

KIRCHENPAUER, G.H. 1864. Neue Sertulariden aus verschiedenen Hamburgischen Sammlungen, nebst allgemeinen Bemerkungen über Lamouroux's Gattung Dynamena. Verh. Kaiserlich. Leopoldino-Carol. Dtsch. Akad. Naturforsch. 31(3):1-16.

KIRCHENPAUER, G.H. 1872. Ueber die hydroidenfamilie Plumularidae, einzelne gruppen derselben und ihre fruchtbehälter. Abh. Geb. Naturw. 5(3): $1-52$.

KÜHN, A. 1913. Entwicklungsgeschichte und verwandtschaftsbeziehungen der Hydrozoen. I. Teil: Die Hydroiden. Ergebn. Fortschr. Zool. 4:1-284. 
LAMOUROUX, J.V.F. 1812. Extrait d'un mémoire sur la classification des polypiers coralligènes non entièrement pierreux. Nouv. Bull. Soc. Sci. philom. 3:181-188.

LAMOUROUX, J.V.F. 1816. Histoire des polypiers coralligènes flexibles, vulgairement nommés zoophytes. F. Poisson, Caen.

LAMOUROUX, J.V.F. 1824. Description des polypiers flexible. In Voyage autour du monde, entrepris par ordre du Roi, exécuté sur les corvettes de S.M. l'Uranie et la Physicienne, pendant les années 1817, 1818, 1819 et 1820 (J.R.C. Quoy \& J.P. Gaimard, eds). Pillet Aîné, Paris, p.603-643.

LELOUP, E. 1935. Hydraires calyptoblastiques des Indes Occidentales. Mém. Mus. r. Hist. nat. Belg. 10:1-73.

LINNAEUS, C. 1758. Systema naturae per regna tria naturae, secundum classes, ordines, genera, species cum characteribus, differentiis, synonymis, locis. 10nd ed. British Museum Natural History, London.

LÜTKEN, C. 1850. Nogle bemaerkninger om medusernes systematiske Inddeling, navnlig med hensyn til Forbes's history of Brittish naked-eyed medusae. Vidensk. Meddr. dansk naturh. Foren. 1850:15-35.

MACGILLIVRAY, J. 1842. Catalogue of the marine zoophytes of the neighbourhood of Aberden. Ann. Mag. Nat. Hist. 9:462-469.

MARKTANNER-TURNERETSCHER, G. 1890. Die hydroiden des K.K. Naturhitorischen Hofmuseums. Annln. naturh. Mus. Wien 5:195-286.

MARQUES, A.C., MERGNER, H., HÖINGHAUS, R. \& VERVOORT, W. 2000. Bimeria vestita (Hydrozoa: Anthomedusae: Bougainvilliidae) senior synonym of Eudendrium vestitum (Hydrozoa: Anthomedusae: Eudendriidae). Zool. Meded. 73(22):321-325.

MARQUES, A.C. 2001. O gênero Eudendrium (Hydrozoa, Anthomedusae, Eudendriidae) no Brasil. Pap. Avulsos Zool. 41(22):329-405.

MARQUES, A.C. \& MIGOTTO, A.E. 2003. Hidrozoários (Cnidaria) marinhos bentônicos da estação ecológica Juréia-Itatins. In Estação Ecológica Juréia-Itatins, ambiente físico, flora e fauna (O.A.V. Marques $\&$ W. Duleba eds). Holos Editora, Ribeirão Preto, p.172-178.

MARQUES, A.C., MORANDINI, A.C. \& MIGOTTO, A.E. 2003. Synopsis of knowledge on Cnidaria Medusozoa from Brazil. Biota Neotrop. 3(2): http://www.biotaneotropica.org.br/v3n2/pt/fullpaper?bn01203022003+en (último acesso em 16/02/2011)

MARQUES, A.C. \& LAMAS, C.J.E. 2006. Sistemática zoológica no Brasil: estado da arte, expectativas e sugestões de ações futuras. Pap. Avulsos Zool. 46:139-172.

MARQUES, A.C., SHIMABUKURO, V., MORANDINI, A.C. \& MIGOTTO, A.E. 2006. Cnidaria Medusozoa do litoral do estado do Ceará. In Biota Marinha da Costa Oeste do Ceará (H. Matthews-Cascon, H. \& T.M.C. Lotufo, eds.). Ministério do Meio Ambiente, Brasília, Série Biodiversidade, p.71-112.

MARQUES, A.C., PEÑA CANTERO, A.L., MIRANDA, T.P. \& MIGOTTO, A.E. (2011). Revision of the genus Filellum Hincks, 1868 (Lafoeidae, Leptothecata, Hydrozoa). Zootaxa.

MAYAL, E.M. 1983. Distribuição de hidróides (Hydrozoa, Thecata) na costa do estado de Pernambuco, Brasil. Bol. zool. 6:1-13.

McCRADY, J. 1859a. Gymnopthalmata of Charleston Harbor. Proc. Elliott Soc. nat. Hist. 1:103-221.

McCRADY, J. 1859b. Description of Oceania (Turritopsis) nutricula nov. spec. and the embryological history of a singular medusan larva, found in the Cavity of its bell. Proc. Elliott Soc. nat. Hist. 1:55-90.

MIGOTTO, A.E. \& DA SILVEIRA, F.L. 1987. Hidróides (Cnidaria, Hydrozoa) do litoral sudeste e sul do Brasil: Halocordylidae, Tubulariidae e Corymorphidae. Iheringia 66:95-115.

MIGOTTO, A.E. 1996. Benthic shallow-water hydroids (Cnidaria, Hydrozoa) of the coast of São Sebastião, Brazil, including a checklist of Brazilian hydroids. Zool. Verh. 306:1-125.

Migotto, A.E., MARQUeS, A.C., MORAndini, A.C. \& DA SILVEIRA, F.L. 2002. Checklist of the Cnidaria Medusozoa of Brazil. Biota Neotrop. 2(1): http://www.biotaneotropica.org.br/v2n1/pt/ fullpaper?bn01102012002+en (último acesso em 16/02/2011)
MIGOTTO, A.E., MARQUES, A.C. \& OLIVEIRA, O.M.P. 2004. Classe Hydrozoa. In Biodiversidade bentônica da região sudeste-sul do Brasil - plataforma externa e talude superior (A.C.Z. Amaral \& C.L.B. RossiWongtschowski, eds). Instituto Oceanográfico, São Paulo, p.65-68.

MIGOTTO, A.E. \& MARQUES, A.C. 2006. Invertebrados marinhos. In Avaliação do Estado do Conhecimento da Biodiversidade Brasileira (T.M. Lewinsohn, ed.). Ministério do Meio Ambiente, Brasília, p.149-202.

MILLARD, N.A.H. \& BOUILLON, J. 1973. Hydroids from the Seychelles (Coelenterata). Annls Mus. R. Afr. Centrale 8:1-106.

MILLARD, N.A.H. 1975. Monograph on the hydroida of Southern Africa. Ann. S. Afr. Mus. 68:1-513.

NUTTING, C.C. 1900. American hydroids. Part I: the Plumularidae, with thirty-four plates. Spec. Bull. U.S. natn. Mus. 4(1):1-285.

NUTTING, C.C. 1915. American hydroids. Part III: the Campanularidae and the Bonneviellidae, with twenty-seven plates. Spec. Bull. U.S. natn. Mus. 4(6):1-126.

OLIVEIRA, O.M.P., MARQUES, A.C. \& MIGOTTO, A.E. 2006. Chave de identificação dos hidróides (Cnidaria, Hydrozoa) epifíticos do Canal de São Sebastião (SE, Brasil). Biota Neotrop. 6(2): http://www. biotaneotropica.org.br/v6n2/pt/fullpaper?bn02306022006+pt (último acesso em 12/04/2011).

OLIVEIRA, O.M.P. \& MARQUES, A.C. 2007. Epiphytic hydroids (Hydrozoa: Anthoathecata and Leptothecata) of the world. Check List 3:21-38.

OLIVEIRA, O.M.P., ARAÚJO, E.M., AYON, P., CEPEDA, A.A., GALEA, H., GENZANO, G.N., HADDAD, M.A., MIANZAN, H.W., MIGOTTO, A.E., MIRANDA, L.S., MIRANDA, T.P., MONTECINOS, P.C., MORANDINI, A.C., NAGATA, R.M., NOGUEIRA JUNIOR, M., QUIÑONES, J.A.D., PALMA, S., RODRIGUEZ, C., STAMPAR, S.N., SCHIARITI, A., TRONOLONE, V.B. \& MARQUES, A.C. (no prelo). Synopsis and annotated checklist of the Cnidaria (Ceriantharia and Medusozoa) and Ctenophora from South America.

PALLAS, P.A. 1766. Elenchus zoophytorum sistens generum adumbrationes generaliores et specierum cognitarum succinctas descriptiones cum selectis auctorum synonymis. Hagae, Fransiscum Varrentrapp, Frankfurt.

PALLAS, P.S. 1774. Spicilega zoological quibus novae imprimus et obscurae animalius species. August Lange, Berolini, Fasc.10.

PEÑA CANTERO, A.L., SVOBODA, A. \& VERVOORT, W. 2004. Antarctic hydroids (Cnidaria, Hydrozoa) of the families Campanulinidae, Lafoeidae and Campanulariidae from recent Antarctic expeditions with R.V. Polarstern, with the description of a new species. J. Nat. Hist. 38:2269-2303.

PIRES, D., CASTRO, C.B., MIGOTTO, A.E. \& MARQUES, A.C. 1992. Cnidários bentônicos do Arquipélago de Fernando de Noronha, Brasil. Bol. Mus. Nac. 354:1-21.

PRÉVOT, E. 1959. Morphologie et évolution des structures tentaculaires chez les hydraires gymnoblastes Capitata. Recl. Trav. Stn. mar. Endoume 29:91-126.

ROTCH, W.D. 1871. On a new genus and species of hydroid zoophyte. Ann. mag. nat. hist. 7:227-228.

SARS, M. 1851. Beretning om en i sommeren 1849 foretagen zoologisk reise i lofoten og finmarken. Nyt. Mag. Naturvid. 6:121-211.

SCHUCHERT, P. 2011. The Hydrozoa directory. http://www.ville-ge.ch/ mhng/hydrozoa/hydrozoa-directory.htm (último acesso em 11/04/11).

SHIMABUKURO, V. \& MARQUES, A.C. 2006. Morphometrical analysis, histology, and taxonomy of Thyroscyphus ramosus (Cnidaria, Hydrozoa) from the coast of Brazil. Zootaxa 1184:29-42.

SHIMABUKURO, V., MARQUES, A.C. \& MIGOTTO, A.E. 2006. Fauna de hidrozoários atecados (Hydrozoa, Anthoathecata) da costa do Estado do Ceará, Brasil. Biota Neotrop. 6(3): http://www.biotaneotropica.org. br/v6n3/pt/fullpaper?bn00806032006+pt (último acesso em 16/02/2011)

STECHOW, E. 1921. Neue genera und species von hydrozoen und anderen evertebraten. Arch. Naturgesch 87:248-265. 
STEENSTRUP, J.J.S. 1854. En ny og tropisk Art af Smaagoplernes Ammeslaegt: Corymorpha Sars (Corym. Januarii Stp.). Vidensk. Meddr dansk naturh. Foren. 1854(1-3):46-48.

VANNUCCI MENDES, M. 1946. Hydroida thecaphora do Brasil. Arq. zool. Est. São Paulo 4(14):535-598.

VANNUCCI, M. 1949. Hydrozoa do Brasil. Bol. Fac. Filos. Cienc. Let. Univ. São Paulo 14:219-266.

VANNUCCI, M. 1950. Resultados científicos do Cruzeiro do "Baependi" e do "Vega" à Ilha da Trindade. Hydrozoa. Bol. Inst. Paul. Oceanogr. $1(1): 81-96$

VANNUCCI, M. 1951. Hydrozoa e Scyphozoa existentes no Instituto Paulista de Oceanografia. Bol. Inst. Paul. Oceanogr. 2(1):69-100.

VANNUCCI, M. 1954. Hydrozoa e Scyphozoa existentes no Instituto Oceanográfico. Bol. Inst. Oceanogr. 5(1-2):95-149.

VANNUCCI, M. 1957. On Brazilian hydromedusae and their distribution in relation to different water masses. Bol. Inst. Oceanogr. 8(1-2):23-109.
VANNUCCI, M. \& REES, W.J. 1961. A revision of the genus Bougainvillia (Anthomedusae). Bol. Inst. Oceanogr. 11(2):57-100.

VANNUCCI, M. \& RIBEIRO, L.C. 1955. O ciclo reprodutivo de Clytia cylindrica L. Agass., 1862 (Hydrozoa: Campanulariidae). Dusenia 6(3-4):69-81.

WARREN, E. 1908. On Tubularia solitaria sp. nov., a hydroid from the Natal coast. Ann. Natal Mus. 1:83-96.

WATSON, J.E. 1985. The genus Eudendrium (Hydrozoa: Hydroida) from Australia. Proc. R. Soc. Vict. 97:179-221.

WATSON, J.E. 2005. Hydroids of the archipelago of the recherche and esperance, western Australia: annotated list, redescription of species and description of new species. In The Marine Flora and Fauna of Esperance, Western Australia (F.E. Wells, D.I. Walker \& G.A. Kendrick, eds). Western Australian Museum, Perth, p.495-612.

WRIGHT, M.D. 1859. Observations on British zoophytes. Edinb. New phil. J. 10:105-114.

Recebido em 18/04/2011

Versão reformulada recebida em 13/07/2011

Publicado em 31/08/2011 